(C2020. This manuscript version is made available under the CC-BY-NC-ND 4.0 license http://creativecommons.org/ licenses/by-nc-nd/4.0/

\section{1}

2

3

4

5

6

\title{
Esterification of residual palm oil using solid acid catalyst derived from rice husk
}

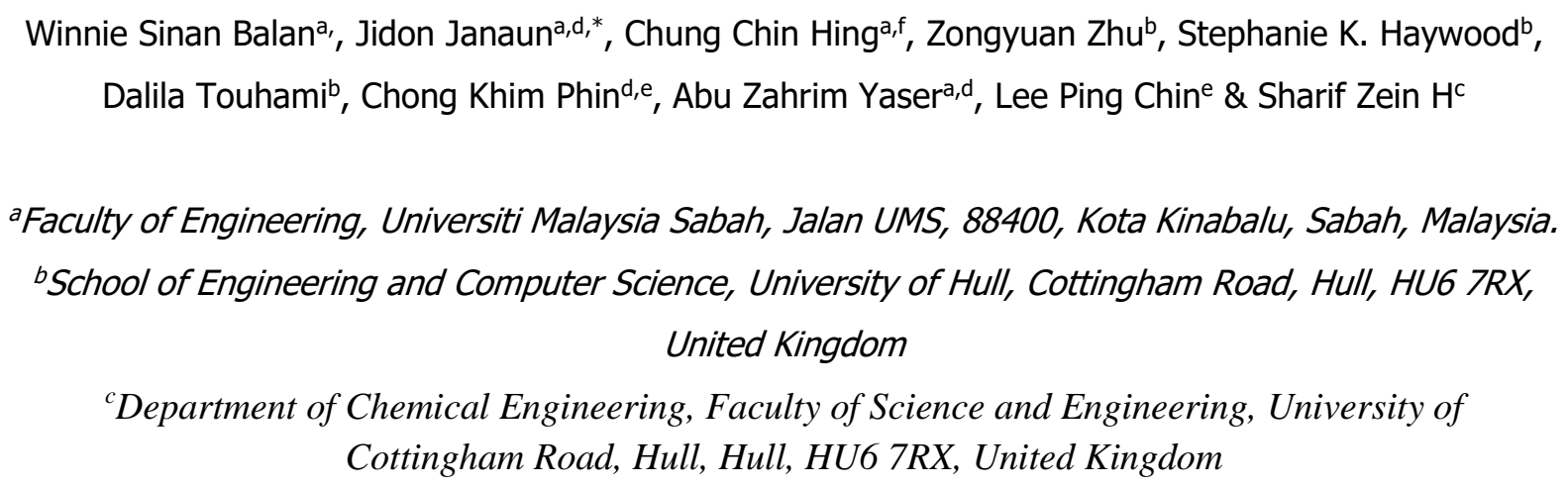

${ }^{\text {a} S u s t a i n a b l e ~ P a l m ~ O i l ~ R e s e a r c h ~ U n i t ~(S P O R), ~ U n i v e r s i t i ~ M a l a y s i a ~ S a b a h, ~ J a l a n ~ U M S, ~ 88400, ~ K o t a ~ K i n a b a l u, ~}$ Sabah, Malaysia

eFaculty of Science and Natural Resources, Universiti Malaysia Sabah, Jalan UMS, 88400, Kota Kinabalu, Sabah, Malaysia.

${ }^{f}$ Biosain Technologies Sdn. Bhd., Block 11, Lot 94, Ground Floor, Phase 11, Prima Square, Batu 4, Jalan Utara, P. O. Box 77, 90701 Sandakan, Sabah, Malaysia.

*Corresponding author: jidon@ums.edu.my

\section{Abstract}

In this study, carbon-silica based acid catalysts derived from rice husks $(\mathrm{RH})$ were successfully synthesized using microwave (MW) technology. The results showed that MW sulphonation produced Sulfur (S) content of 17.2 - 18.5 times higher than in raw RH. FTIR showed peak at $1035 \mathrm{~cm}^{-1}$ which corresponded to $\mathrm{O}=\mathrm{S}=\mathrm{O}$ stretching of sulphonic $\left(-\mathrm{SO}_{3} \mathrm{H}\right)$ group. Peak related to silica $\left(788 \mathrm{~cm}^{-1}\right)$ remained even after MW pyrolysis and sulphonation. XRD showed sulfonated RH catalysts (SRHCS) have amorphous structure, and through SEM, broadening of the RH voids and also formation of pores is observed. SRHCs were mesoporous with pore diameter ranging from $3.89 \mathrm{~nm}$ to $5.41 \mathrm{~nm}$. SRHCs showed high catalytic activity for esterification of oleic acid with methanol with RH600 had the highest initial formation rate $\left(6.33 \mathrm{mmol} \cdot \mathrm{L}^{-1} \cdot \mathrm{min}^{-1}\right)$ and yield (97\%). The reusability of the catalyst showed gradual dropped in yield for every reused, which might due to leaching of $-\mathrm{SO}_{3} \mathrm{H}$. Finally, esterification of oil recovered from Palm Oil Mill Effluent (POME) 
with methanol achieved a conversion of $87.3 \%$ free fatty acids (FFA) into fatty acid methyl esters (FAME).

\section{Keywords}

Microwave pyrolysis, Palm Oil Mill Effluent, Fatty Acid Methyl Esters, - $\mathrm{SO}_{3} \mathrm{H}$, Sulphonation

\section{Introduction}

Malaysia is the second largest palm oil producer after Indonesia [1, 2]. In year 2016, palm oil industry in Malaysia alone, produces approximately 20 million ton crude palm oil (CPO) [2]. For every ton of CPO produced, about 2.5-3.5 ton of wastewater, known as palm oil mill effluent (POME) will be generated [3], and approximately 50 million $\mathrm{m}^{3}$ of POME produced, annually.

POME is a brownish wastewater comprises of $95-96 \%$ water, $0.6-0.7 \%$ residual palm oil and $4-5 \%$ total solids, including $2-4 \%$ suspended solid [4]. It also has high BOD and COD value, about 25, $000 \mathrm{mg} / \mathrm{L}$ and 50, $000 \mathrm{mg} / \mathrm{L}$, respectively $[4,5]$. In addition to that, the residual palm oil in POME is mostly in emulsion form [3] and it has high stability in water [6]. Discharge of POME to the public through waterways without first being treated will cause a serious hazard to the ecosystem.

The properties of residual oil in POME are comparable to CPO, except it has higher free fatty acid (FFA) ( 7.7\%) and moisture content ( 2.4\%) [7]. FFA content and moisture content varies in each mill. About $\sim 350,000 \mathrm{~m}^{3} /$ year of emulsified oil is available in POME and can be value added. Based on review, physical sorbent like membrane, can remove oil and grease at a high rate $[8,9]$. Studies show that polypropylene micro/nanofiber (PP MNF) is capable of adsorbing emulsified oil and can be easily desorbed by physical pressing method [10, 11]. In real POME system, it has a recovery capacity of $12.19 \mathrm{~g}$ oil $/ \mathrm{g}$ of fiber [10]. The recovered residual palm oil has a comparable property to that of crude palm oil, hence it can be used for many applications.

Biodiesel is an alternative fuel that can be derived from any feedstock containing triglycerides (TG) and/or FFA [12]. Biodiesel or fatty acid methyl ester (FAME) can be produced through several methods such as transesterification, esterification, supercritical, etc., of any feedstock with methanol producing FAME with or without catalyst [13]. In Malaysia context, palm oil is the most suitable feedstock for biodiesel production due to the abundant source available. However, palm oil is expensive, and it may cause competition with food source. Hence, residual 
67 palm oil recovered from POME is a good feedstock for making biodiesel. In this study, the residual

68 palm oil was used to produce biodiesel via esterification reaction.

Studies showed that D-glucose derived solid acid catalyst is capable of converting high FFA content feedstocks into FAME and it is less sensitive to water [14-16]. It was reported that

71 pyrolysis of D-glucose at optimum temperature of $400^{\circ} \mathrm{C}$ produced an amorphous carbon, which

72 can be easily functionalized and has high reactivity [14]. Carbon-based catalyst can also be

73 derived from lignocellulosic material such as a biomass [17]. Rice husk (RH) is used as the

74 biomass source in this study because it is readily available in large quantity as a waste from rice 75 processing mills, the content is mainly composed of carbon and silica which are the essential 76 ingredients for making solid acid catalyst, and naturally has a high surface area [18]. However, 77 pyrolysis using conventional heating is time and energy consuming. Pyrolysis through irradiation 78 heating using microwave (MW) was reported to be fast and efficient, as well as producing better 79 properties of char [18]. Therefore, in this study, catalysts derived from RH will be synthesized 80 using MW technology. The activity of synthesized catalysts will be evaluated through esterification 81 of oleic acid and methanol. Finally, the performance of the catalysts converting FFA in oil 82 recovered from POME into FAME will also be tested through esterification with methanol.

$84 \quad$ 2. Experimental

\subsection{Recovery of oil from POME}

Oil was recovered from POME by using PP MNF. PP MNF was produced in Faculty of Engineering, Universiti Malaysia Sabah using melt-blown technique in Nanotechnology Laboratory. PP MNF used was an oleophilic material. It has a stronger affinity for oils compared to water. To enhance oleophilicity of PP MNF, it was pre-oiled with $\mathrm{CPO}$ and pressed using a roller press to remove excessive CPO. Subsequently, pre-oiled PP MNF was placed in a $208 \mathrm{~L}$ tank filled with POME. After $3 \mathrm{~h}$ of contact time, the PP MNF was removed from the tank and pressed. The oil obtained was collected into a $500 \mathrm{~mL}$ blue cap DURAN glass bottle and stored in a refrigerator at temperature $4^{\circ} \mathrm{C}$ until use.

\subsection{Characterization of POME}

\subsubsection{Density}


97 Density of oil recovered from POME was determined prior to esterification reaction. Oil was 98 separated naturally by gravity. The top layer was slowly decanted and heated again to $35^{\circ} \mathrm{C}$ on a hot plate and gently stirred using a magnetic stirrer.

Density of oil was determined by using a $25 \mathrm{~mL}$ pycnometer density bottle. The weight of

101

102

103 104

105

106

107

108

109

110

111

112

113

114

115

116 where,

117 A is volume of $\mathrm{NaOH}$ used, in milliliters $(\mathrm{mL})$;

$118 \mathrm{~N}$ is normality of $\mathrm{NaOH}$; and

119 W is weight of the oil sample, in grams (g).

\subsubsection{Saponification value}

122 Approximately $2 \mathrm{~g}$ of the sample was weighed into a conical flask. Then, $25 \mathrm{~mL}$ of 123 the ethanolic potassium hydroxide solution $(0.5 \mathrm{~mol} / \mathrm{L}$ solution on $95 \%(\mathrm{v} / \mathrm{v})$ ethanol was added 124 to the portion. The flask was connected to the reflux condenser and placed on the heating device 125 and boil gently at temperature $50^{\circ} \mathrm{C}$ and stirred. After $60 \mathrm{~min}, 0.5 \mathrm{~mL}$ of phenolphthalein solution was added into the hot solution and titrated with $0.5 \mathrm{~mol} / \mathrm{L}$ of volumetric hydrochloric $(\mathrm{HCl})$ acid 
solution until the pink colour of the indicator just disappears. Blank test was also being carried out using $25 \mathrm{~mL}$ of $0.5 \mathrm{~mol} / \mathrm{L}$ of volumetric $\mathrm{HCl}$ solution omitting the test portion. Saponification value equation is shown in equation below.

$$
\text { Saponification value, SV }=\frac{(\text { Vo-Vi }) \times C \times 56.1}{m}
$$

\section{Equation 2}

where, $V_{o}$ is the volume, in milliliters $(\mathrm{mL})$, of $0.5 \mathrm{~mol} / \mathrm{L} \mathrm{HCl}$ solution used for the blank test; $V_{i}$ is the volume, in milliliters $(\mathrm{mL})$, of $0.5 \mathrm{~mol} / \mathrm{L}$ HClsolution used for the determination; $\mathrm{C}$ is the exact concentration, in moles per litre ( $\mathrm{mol} / \mathrm{L}$ ) of the volumetric $\mathrm{HClsolution}$; and $\mathrm{m}$ is the weight of the sample, in gram ( $\mathrm{g}$ ).

\subsection{Preparation of RH catalysts}

\subsubsection{Washing of $\mathrm{RH}$}

$\mathrm{RH}$ was collected from a local rice mill. Raw RH contained dirt and impurities due to the milling process. To remove the impurities, $\mathrm{RH}$ was rinsed prior to pyrolysis. Approximately $100 \mathrm{~g}$ of rinsed $\mathrm{RH}$ was weighed onto a $2 \mathrm{~L}$ beaker and then filled with distilled water. Subsequently, the mixture was manually stirred and RH was filtered using mesh to remove excess water. Washing steps were repeated a few times until the colour of the washed water was comparable to the distilled water. The washed $\mathrm{RH}$ was dried overnight in an oven at temperature $103 \pm 2^{\circ} \mathrm{C}$. Then, the dried $\mathrm{RH}$ was cooled to ambient temperature in a desiccator for $\mathbf{4 0} \mathrm{min}$. It was stored in a sealed plastic in a desiccator until next process.

\subsubsection{MW set-up}

Catalyst derived from $\mathrm{RH}$ was prepared by two-step process. The first step was pyrolysis of $\mathrm{RH}$, followed by sulphonation of char. Both processes were conducted in a conventional MW operated at a frequency of $2450 \mathrm{MHz}$, with the lowest operating power of $100 \mathrm{~W}$ and the highest was 800 W The MW had been modified and the set-up is as shown in Figures 1 and 2. A $500 \mathrm{~mL}$ twonecked round bottom flask was placed at the centre of MW chamber. Two holes were created at the top part of the MW to fit in glass connectors. For safety purpose, the size of the holes was 
159 small enough just to fit the connectors to avoid leakage of MW radiation. The function of the 160 connectors was to allow $\mathrm{N}_{2}$ gas to flow in and out of the system. A hose for $\mathrm{N}_{2}$ gas was connected 161 to one of the glass connectors. The other glass connector was connected to a $500 \mathrm{~mL}$ beaker 162 filled with approximately $400 \mathrm{~mL}$ of $1 \mathrm{M} \mathrm{NaOH}$ solution for neutralization of $\mathrm{H}_{2} \mathrm{SO}_{4}$ vapour during 163 pyrolysis process. This MW set-up was placed in a fume hood throughout the operation. Pyrolysis 164 and sulphonation processes were conducted in a fume hood chamber.

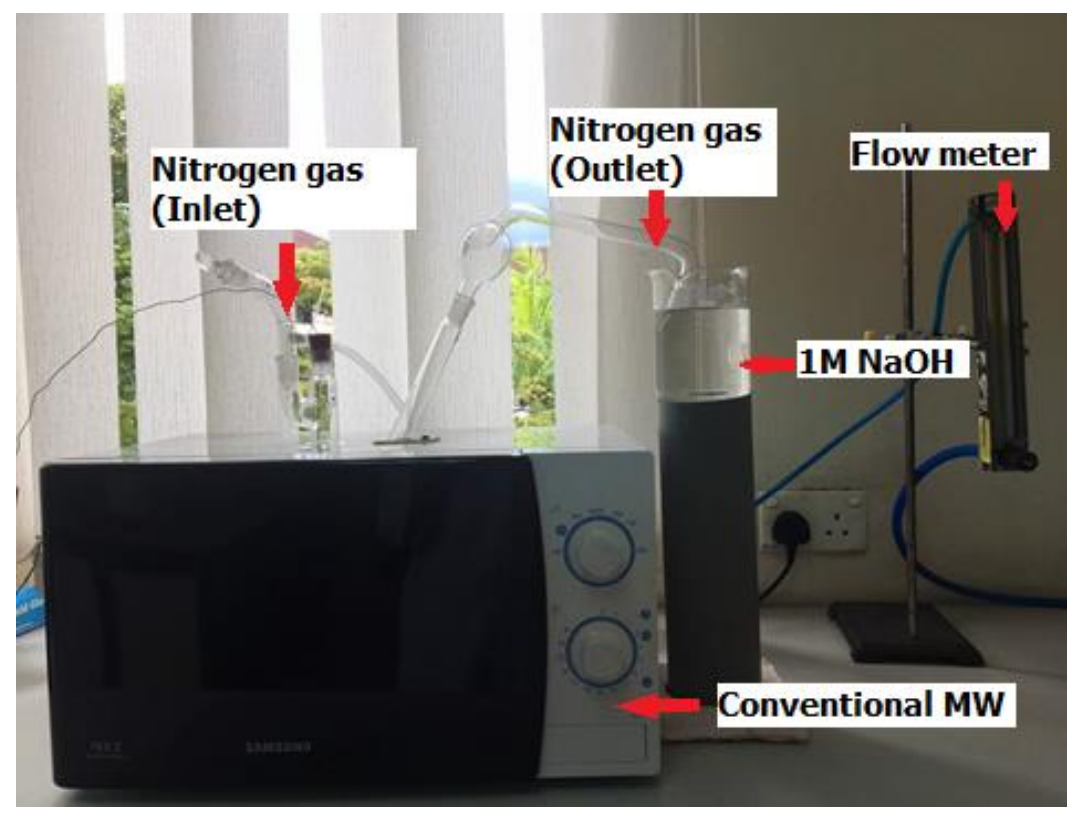




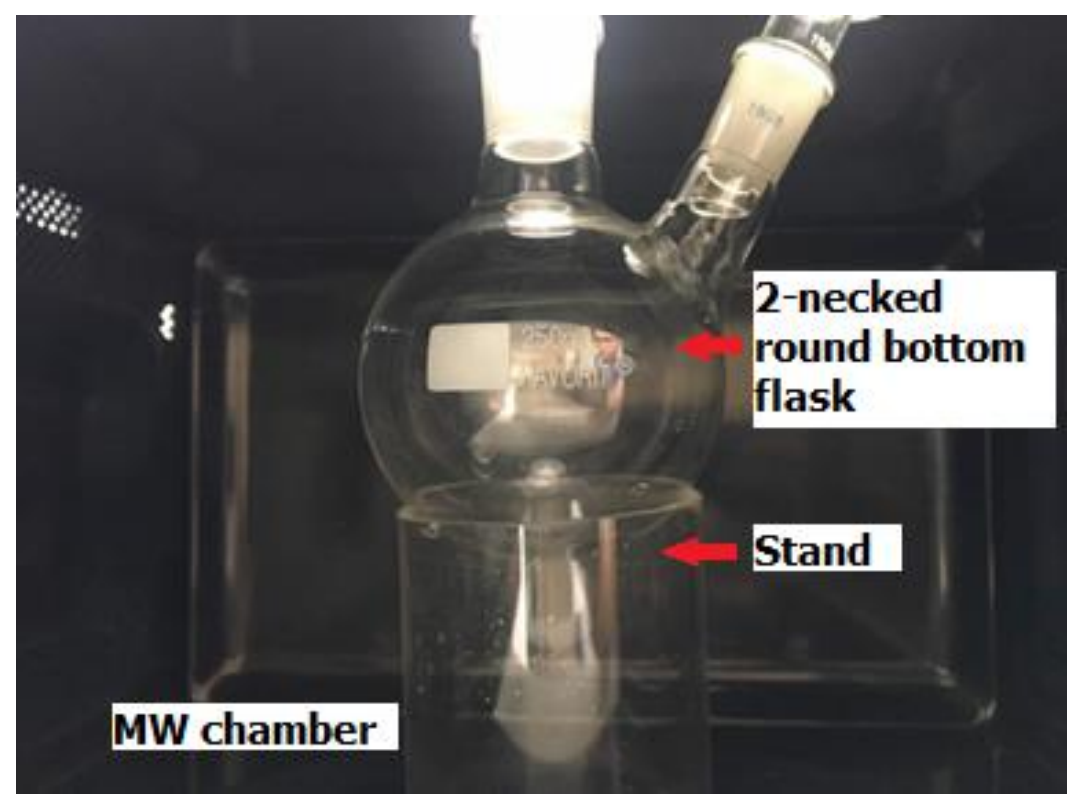

Figure 2: Glass round bottom flask in MW chamber.

\subsubsection{MW assisted catalyst preparation}

3 grams of washed and dried $\mathrm{RH}$ was soaked in $30 \mathrm{~mL}$ of $1 \mathrm{M} \mathrm{H}_{2} \mathrm{SO}_{4}$ solution for $5 \mathrm{~min}$ and stirred. Then, it was filtered to remove excessive acid solution. The addition of $1 \mathrm{M} \mathrm{H}_{2} \mathrm{SO}_{4}$ solution was referred to the method used by Touhami et. al.[18]. Dilute $\mathrm{H}_{2} \mathrm{SO}_{4}$ acted as $\mathrm{MW}$ absorber to assist reduction of activation energy for the pyrolysis of $\mathrm{RH}[20,21]$. Filtered $\mathrm{RH}$ then filled into a 500 $\mathrm{mL}$ round bottom flask and placed in the MW chamber. $\mathrm{N}_{2}$ gas (99.99\% purity) was purged into the system with a flow rate of $100 \mathrm{~mL} / \mathrm{min}$ for $10 \mathrm{~min}$ to keep system in an inert atmosphere. Subsequently, the MW power level was switched to power level of 200, 300, 450, 600 and 700 $\mathrm{W}$ for $30 \mathrm{~min}$. $\mathrm{N}_{2}$ gascontinued to flow during this process.After pyrolysis, resulting bio-chars, also known as RHCS, were cooled down naturally to room temperature. Then, the RHCs were collected and unburned particles were removed (if any) manually using a forcep.

The collected RHC then underwent sulphonation. RHC was filled into the round bottom flask followed by concentrated sulfuric acid (98\%) at the ratio of $1: 10(\mathrm{w} / \mathrm{v})$ [22], and placed at the center of the MW chamber. The system was first purged with $\mathrm{N}_{2}$ gas (99.99\% purity) for 10 min at a flow rate of $100 \mathrm{~mL} / \mathrm{min}$ to create an inert atmosphere. For sulphonation, the sample was heated at power $100 \mathrm{~W}$ for 20 min under $100 \mathrm{~mL} / \mathrm{min} \mathrm{N}_{2}$ gas flow. Then, the sample was cooled to ambient temperature naturally. Subsequently, the sulphonated RH char (SRHC) was removed from the flask and filtered. The char was washed with warm distilled water $\left(80^{\circ} \mathrm{C}\right)$ 
repeatedly until $\mathrm{pH}$ turned neutral and dried overnight in oven at temperature $103 \pm 2^{\circ} \mathrm{C}$. All synthesized SRHCs were named RH200, RH300, RH450, RH600 and RH700.

\subsection{Characterizations of catalysts}

\subsubsection{Elemental compositions}

$\mathrm{C}, \mathrm{H}, \mathrm{N}, \mathrm{S}$ ratio of $\mathrm{RH}$ and SRHCs were analyzed using a vario MICRO cube, Elementar. The sample was weighed directly into tin crucible and was wrapped. The tin crucible was then placed in an auto-sampler sample holder. Then, the tin crucible was injected into a very high temperature furnace. $\mathrm{O}_{2}$ gas and $\mathrm{He}$ gas were supplied to the furnace and the temperature used for combustion was $1050^{\circ} \mathrm{C}$.

\subsubsection{Functional group}

The functional groups of $\mathrm{RH}$ and SRHCs were analyzed by attenuated total reflection-Fourier transformed infrared spectroscopy (ATR-FTIR) using an Agilent Cary 630 FTIR. The diamond ATR sensor was cleaned with ethanol before analyzing each sample. The sample was then placed on the sensor surface and pressed firmly using a sample press to ensure a good contact between samples which were in powder form with the ATR sensor. The spectral range was between 650 $\mathrm{cm}^{-1}$ to $4000 \mathrm{~cm}^{-1}$.

\subsubsection{Carbon structure}

The crystal structure of RH and SRHCs were determined using X-Ray Diffraction (XRD) analysis (Rigaku, model Miniflex II). The model was operated at $30 \mathrm{kV}, 11 \mathrm{~mA}$ using $\mathrm{Cu} \mathrm{Ka}$ ray and scan speed of $0.015 \%$ s. The Bragg angle was in a range of $10^{\circ}-80^{\circ}$.

\subsubsection{Surface morphology and element detection}

The surface morphologies of RH and SRHCs were observed by using scanning electron microscope (SEM) S-3400N Hitachi. Before the analysis begun, the sample was first placed on a carbon tape and coated with gold using a Q 150R S sputter coater from Quorum. Then, the tape was placed in the SEM sample holder and further analyzed. Images obtained were under vacuum mode of $15 \mathrm{kV}$ acceleration voltage. SEM S-3400N Hitachi was integrated with EDX. Thus, SEM and EDX analysis was done simultaneously. EDX detected the elements present on selected point on the 
222 sample surface. The operating condition of EDX was similar to SEM. Two points were selected

223 for analysis, one at the outer surface of RH and SRHCs, and the second point was at the inner

224 surface of the materials.

225

\subsubsection{Specific surface area and pore volume}

227 Specific surface area and pore volume of RH and SRHCs were determined by physical adsorption 228 and desorption of nitrogen using ASAP 2020 Micromeritics. Prior to analysis, the sample was degassed at temperature $110^{\circ} \mathrm{C}$ for $3 \mathrm{~h}$. The resulting isotherms were analyzed using BrunauerEmmett-Teller (BET) model to calculate the specific surface area. Meanwhile, total pore volume of the sample was evaluated from isotherms using Barrett-Joyner-Halenda $(\mathrm{BJH})$ model.

\subsection{Esterification of oleic acid}

234 Catalytic esterification of oleic acid and methanol was performed in a bench reactor, STEM Omni 235 Reactor MK-II. A molar ratio of 1:12 (oleic acid to methanol) was used in this reaction. The mixture was heated to $60^{\circ} \mathrm{C}$ and stirred with a stirring speed of $1200 \mathrm{rpm}$. Then, 5 wt.\% (w.r.t 237 to oleic acid) of SRHC was weighed and added to the mixture. This reaction was conducted for $23812 \mathrm{~h} .100 \mu \mathrm{L}$ of the sample was pipetted at every interval of reaction times $\left(1^{\text {st }}, 2^{\text {nd }}, 4^{\text {th }}, 7^{\text {th }}, 10^{\text {th }}\right.$ 239 and $12^{\text {th }} \mathrm{h}$ ) and injected into $5 \mathrm{~mL}$ volumetric flasks for product analysis. Esterification of oleic acid catalyzed by sulfuric acid was also conducted for comparison, the reaction condition used was similar as SRHC, except, the reaction time was only $2 \mathrm{~h}$. Sampling were done at every 30 min interval.

245 Product samples were qualitatively analyzed using GC (7890B Network GC System) equipped with 246 a flame ionization detector (FID) and a HP-5 column (30 m x $320 \mu \mathrm{m} \times 0.25 \mu \mathrm{m})$ from Agilent 247 Technologies. Prior to analysis, the product was diluted with n-heptane (99\%, Merck) and filtered 248 using a $5 \mathrm{~mL}$ syringe fitted with a $0.45 \mu \mathrm{m}$ pore size PTFE filter. $1.5 \mathrm{~mL}$ of filtered sample was 249 filled into a GC vial and ready to be analyzed. $1 \mathrm{uL}$ of the sample was injected into the GC with 250 an injector temperature of $250^{\circ} \mathrm{C}$, split ratio of $25: 1$ and $1 \mathrm{~mL} / \mathrm{min}$ of hydrogen flow as carrier 251 gas. The sample was measured at oven temperature of $100-300^{\circ} \mathrm{C}$, ramped at rate of $50^{\circ} \mathrm{C} / \mathrm{min}$ 252 and hold for $6 \mathrm{~min}$. The detector temperature used was $300^{\circ} \mathrm{C}$. The presence of methyl oleate 253 peak at time 4.99 min was determined. 


\subsubsection{Reusability of catalyst}

256 SRHC was separated from the reaction mixture through centrifugation. The reaction mixture was 257 first poured into a $50 \mathrm{~mL}$ centrifuge vial and then centrifuged at $3500 \mathrm{rpm}$ for $10 \mathrm{~min}$. Liquid samples were decanted and recovered SRHC was washed using double washing method to remove both polar and non-polar compound covering surface and active sites of SRHC [23]. 10 $\mathrm{mL}$ of methanol was poured into the vial and swirled. Then, the mixture was centrifuged at 3500 rpm for 10 min to separate methanol from SRHC. Methanol was then decanted and $10 \mathrm{~mL}$ of $\mathrm{n}$ hexane was added into the vial and swirled. After swirling, SRHC immediately settled down and n-hexane was decanted. Washed SRHC was dried overnight in an oven at temperature of $100^{\circ} \mathrm{C}$. The catalytic performance of recovered SRHC on esterification of oleic acid was tested. For this test, only reusability of RH600 was tested. The reaction condition used was similar as method

\subsection{Esterification of oil recovered from palm oil mill effluent}

\subsubsection{Reaction condition}

271 Esterification of oil recovered from POME was also performed in STEM Omni Reactor MK-II. Due 272 to low miscibility of oil and alcohol, more alcohol was needed to reduce mass transfer limiting 273 factor. Thus, the molar ratio of oil to methanol used for esterification was 1:40. The mixture was 274 heated to $70^{\circ} \mathrm{C}$ and stirred at the stirring rate of $1200 \mathrm{rpm}$. When the temperature reached $70^{\circ} \mathrm{C}$, 2755 wt.\% of catalyst RH600 was added into the mixture. The reaction was let to run for $24 \mathrm{~h}$.

\subsubsection{Product analysis by titration}

278 After the reaction was completed, acid value (AV) of oil was determined by using titration method (section 2.2). Reaction mixture was first centrifuged at $3500 \mathrm{rpm}$ for $10 \mathrm{~min}$ to separate catalyst from liquid. The liquid sample was then poured into a separator funnel and leave to separate for $5 \mathrm{~min}$. Two layers were observed. The top layer was a mixture of water and methanol, meanwhile, mixture of triglycerides and methyl esters was at the bottom layer. Then, liquid at the bottom layer was drained into a $25 \mathrm{~mL}$ beaker. $1 \mathrm{~g}$ of sample from the bottom layer was taken for AV determination. The analysis was repeated 3 times to get the average final AV. Finally, the conversion rate was calculated by using formula below [24]: 
where, initial $A V$ is the $A V$ of oil before esterification reaction and final $A V$ is $A V$ after esterification.

290

291

\section{Results and discussion}

292

293

\subsection{Characterization of catalysts}

\subsubsection{Elemental analysis of RH and SRHCS}

296 Elemental compositions of RH and SHRCs were determined before and after pyrolysis and sulphonation. Table 1 shows $\mathrm{C}, \mathrm{H}, \mathrm{N}, \mathrm{S}$ and $\mathrm{O}$ content in RH and SRHCs. RH was mainly composed of $35.67 \% \mathrm{C}, 5.68 \% \mathrm{H}, 0.41 \% \mathrm{~N}, 0.15 \% \mathrm{~S}$ and $58.09 \% \mathrm{O}$. C, H, N S was determined on dryweight basis and $\mathrm{O}$ was determined by difference. After sulphonation, $\mathrm{C}$ did not show any significant changes in content. Touhami et. al. reported similar trend in C content after sulphonation [18]. Meanwhile, $\mathrm{H}$ and $\mathrm{N}$ contents reduced remarkably. Approximately $50 \%$ of $\mathrm{H}$ content reduction after pyrolysis and sulphonation compared to raw $\mathrm{RH}$. $\mathrm{N}$ content reduced around $50-65 \%$ of the feedstock. The reduction of $\mathrm{H}$ and $\mathrm{N}$ contents might due to the removal of impurities and condensation due to MW pyrolysis [25-27]. S content after sulphonation resulted in 17.2 - 18.5 times higher than the feedstock. This indicates the presence of sulphonic acid, $-\mathrm{SO}_{3}$ on the SRHCS and the success of the MW sulphonation process. Meanwhile, $\mathrm{O}$ shows a slight reduced after MW pyrolysis and sulphonation. Dehydration and condensation reactions during pyrolysis should reduce O content from the feedstock [18]. However, SHRCs did not show significant reduction, especially SRHC pyrolyzed at higher power. Presumably, the presence of $\mathrm{SO}_{3}$ after sulphonation process contributes to the amount of O on SRHCs [28].

Assuming all $\mathrm{S}$ are belong to the sulphonic acid $\left(-\mathrm{SO}_{3} \mathrm{H}\right)$, the density of $\mathrm{SO}_{3} \mathrm{H}$ for all synthesized catalysts will be around $0.80-0.86 \mathrm{mmol} / \mathrm{g}$ [12], [29-31]. To support the results obtained from elemental analyzer FTIR analysis was done in order to determine the presence of

314 functional group, which in this case is $-\mathrm{SO}_{3} \mathrm{H}$. 


\begin{tabular}{|c|c|c|c|c|c|c|}
\hline \multirow{2}{*}{ Samples } & \multicolumn{5}{|c|}{ Elemental composition (wt. \%) } & \multirow{2}{*}{$\begin{array}{c}\mathrm{SO}_{3} \mathrm{H} \text { Density } \\
(\mathrm{mmol} / \mathrm{g})\end{array}$} \\
\hline & $\mathbf{C}$ & $\mathbf{H}$ & $\mathbf{N}$ & $\mathbf{S}$ & $\mathbf{O}^{\mathbf{a}}$ & \\
\hline $\mathrm{RH}$ & 35.67 & 5.68 & 0.41 & 0.15 & 58.09 & - \\
\hline $\mathrm{RH} 200$ & 38.08 & 3.62 & 0.19 & 2.58 & 55.43 & 0.80 \\
\hline RH300 & 37.15 & 3.63 & 0.14 & 2.58 & 56.50 & 0.80 \\
\hline RH450 & 36.63 & 3.64 & 0.13 & 2.66 & 56.94 & 0.83 \\
\hline RH600 & 36.67 & 3.32 & 0.16 & 2.76 & 57.09 & 0.86 \\
\hline RH700 & 35.40 & 3.29 & 0.17 & 2.76 & 58.38 & 0.86 \\
\hline
\end{tabular}

${ }^{a}$ Oxygen was determined by difference

\subsubsection{Functional group}

Chemical changes in RH feedstock after MW pyrolysis and MW sulphonation were determined using FIIR. RH is mainly composed of cellulose, hemicellulose, lignin and amorphous silica [18, 32]. Alkenes, aromatics, esters, and alcohols are typical compounds that can be found in a lignocellulosic material [18]. Figure 3 shows the FTIR spectrum of RH feedstock. Various peaks were detected which correspond to O-Si-O stretching vibrations of silica group $\left(788 \mathrm{~cm}^{-1}\right),-0$ $\mathrm{CH} / \mathrm{C}-\mathrm{O}$ stretch for the $\mathrm{O}-\mathrm{CH}_{3}$ and $\mathrm{C}-\mathrm{OH}$ of sugar unit in cellulose $\left(1034 \mathrm{~cm}^{-1}\right), \mathrm{OH}$ in-plane bending and $\mathrm{CH}$ bending of cellulose and hemicellulose $\left(1373 \mathrm{~cm}^{-1}\right)[18,33,34]$. A pointing peak at $1510 \mathrm{~cm}^{-1}$ could be due to aromatic ring vibrations of lignin [35], and peak at $1634 \mathrm{~cm}^{-1}$ represents the carbonyl group in conjunction with an aromatic ring in lignin [36]. Broad peak at $2923 \mathrm{~cm}^{-1}$ could represent symmetric $\mathrm{C}-\mathrm{H}$ stretch of a lone $\mathrm{C}-\mathrm{H}$ group of tertiary carbon components $\left(\mathrm{R}_{3} \mathrm{C}-\mathrm{H}\right)$, and another broader and weak peak at $3333 \mathrm{~cm}^{-1}$ corresponds $-\mathrm{OH}$ group $[34,37,38]$. silica did not decompose even after subjected to heat and acid treatment [18]. Peaks at wavelength $1034 \mathrm{~cm}^{-1}$ and $1373 \mathrm{~cm}^{-1}$ which correspond to cellulose and hemicellulose had disappeared after the two processes, and a wider and stronger peak appeared at wavelength $1035 \mathrm{~cm}^{-1}$ upon sulphonation of RHC. This indicates the degradation of cellulose and hemicellulose after pyrolysis and sulphonation, and, new peak at $1035 \mathrm{~cm}^{-1}$ could be due to the presence of symmetrical $\mathrm{O}=\mathrm{S}=\mathrm{O}$ stretching of $-\mathrm{SO}_{3} \mathrm{H}$ group $[18,39-41]$. This further confirmed the attachment of $\mathrm{S}$ to $\mathrm{C}$ as claimed in the total acidity result and the increase of $\mathrm{S}$ content in elemental composition after sulphonation. $-\mathrm{SO}_{3} \mathrm{H}$ attached to the $\mathrm{C}$ framework by a covalent bond the increase of S content in elemental composition after sulphonation in Table 1. 
Meanwhile, peaks at $1510 \mathrm{~cm}^{-1}$ and $1634 \mathrm{~cm}^{-1}$ which related to lignin aromatic ring had 344 withered upon MW pyrolysis and sulphonation. New peaks appeared at $1616 \mathrm{~cm}^{-1}$ and $1710 \mathrm{~cm}^{-}$

$345{ }^{1}$ that related to $\mathrm{C}=\mathrm{C}$ stretching of newly formed polyaromatic, and, $\mathrm{C}=\mathrm{O}$ stretching $\left(1710 \mathrm{~cm}^{-1}\right)$ 346 which also suggest the presence of carboxylic acid, a weak acid that produced from sulphonation 347 process $[18,37,40]$. Besides, peak at $3333 \mathrm{~cm}^{-1}$ had withered as well, and the appearance of a 348 broader peak at wavelength $3221 \mathrm{~cm}^{-1}$ would be due phenolic compound, or might as well, due 349 to the presence of hydroxyl groups from sulphonation of RHC [36]. Figure 4 shows the spectra 350 RH after MW pyrolysis and sulphonation. A wider and intense peak was observed at peak 1035 $351 \mathrm{~cm}^{-1}$ upon sulphonation which due to $\mathrm{O}=\mathrm{S}=\mathrm{O}$ stretching of $-\mathrm{SO}_{3} \mathrm{H}$ group. The results obtained 352 from FTIR analysis further prove the success of functionalizing RHC using modified MW.

353

354

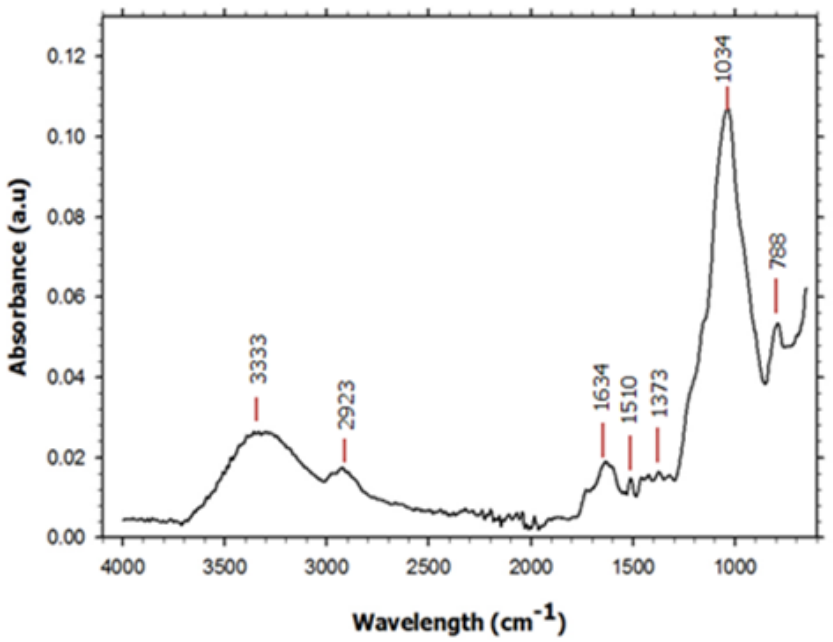

Figure 3: $\quad$ FTIR spectrum of raw RH 


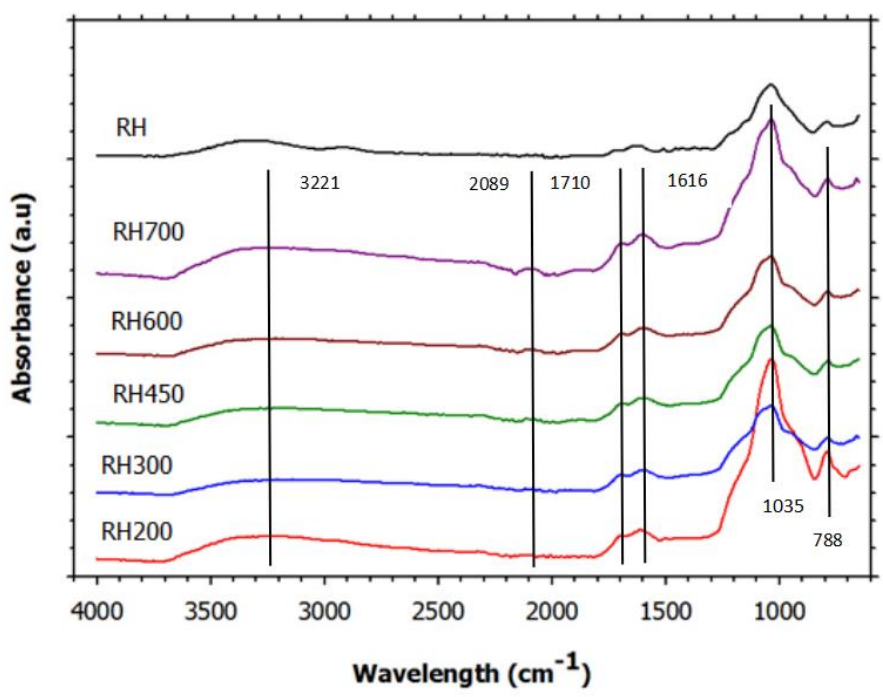

Figure 4: $\quad$ IR spectrum for RH and all MW synthesized catalysts

\subsubsection{Carbon structure}

X-ray diffraction (XRD) analyses of RH and SRHCs were determined using Rigaku, model Miniflex

II. This analysis was done to investigate the carbon structure of RH and SRHCs upon pyrolysis at different temperatures. Figure 5 shows the XRD spectrum of RH and SRHCs. The pattern of RH under XRD analysis is similar to the results reported by other researchers $[18,42]$. The XRD of $\mathrm{RH}$ shows a peak at Braggs $2 \theta$ of around $22^{\circ}$ which is typically indicated silica in $\mathrm{RH}$ [43-45]. A weak peak at around $37^{\circ}$ could be attributed to Si/C composite [44]. The appearance of the broad nature of the peaks may attribute to the large amount of cellulose in $\mathrm{RH}$ [18].

After MW pyrolysis and sulphonation, all SRHCs show significant decrease in intensity at Bragg $2 \theta$ of $20^{\circ}-30^{\circ}$. The results are similar to the findings of Touhami et.al., where the intensity was reduced and broadening of peaks at $20^{\circ}-30^{\circ}$ happened [18]. This infers to the amorphous nature of aromatic carbon sheets, staked in a highly disordered structure, due to the heat treatment and addition of acid $[18,46,47]$. Peak at Braggs $2 \theta=22^{\circ}$ remained after MW pyrolysis and sulphonation but reduced in intensity and broaden. This suggests an amorphous nature. The 374 silica [48].

The XRD profiles of all RH catalysts were almost similar. No crystallinity was observed though subjected to higher power level. Typically reported, highly ordered carbon is obtained by

377 pyrolysis using conventional heating at higher temperature $\left(>450^{\circ} \mathrm{C}\right)$ and longer pyrolysis time $378[14,49,50]$. For MW heating, the maximum temperature and the heating rate depend on the 
material itself $[51,52]$. Huang et. al. reported that the maximum temperature of $\mathrm{RH}$ heated at $500 \mathrm{~W}$ and its heating rate were $517 \pm 42^{\circ} \mathrm{C}$ and $140^{\circ} \mathrm{C} / \mathrm{min}$, respectively [51]. The heating rate for the MW pyrolysis of RH is fast that it reaches a higher temperature in a short time. Though it exceeded the typical temperature for carbon to form a crystalline structure, however MW pyrolysis is a fast process. Thus, formation of larger and highly ordered polycyclic aromatic carbon may not be achieved due to the fast pyrolysis. This might explain the unordered structure of SRHCs although pyrolyzed at a higher power level.

In fact, amorphous structure is desirable for a carbon based catalyst. The unordered structure had a smaller polycyclic aromatic carbon sheet which produced a flexible carbon structure. The proposed structure of unordered carbon was like a crumpled sheet. Thus, more edges available for $\mathrm{SO}_{3} \mathrm{H}$ to anchor to the carbon material. Meanwhile, large and highly ordered carbon sheet has less edge available for $\mathrm{SO}_{3} \mathrm{H}$ to anchor to [14]. This explained why an amorphous carbon structure is more favourable. It is because the amorphous structure is easier to be functionalized by $-\mathrm{SO}_{3} \mathrm{H}$ group. The structures of SRHCs also explained the non-significant changes of total acidity and $\mathrm{SO}_{3} \mathrm{H}$ density at different power level as mentioned above. That was due to the similarity of the structure, though pyrolyzed at different power.

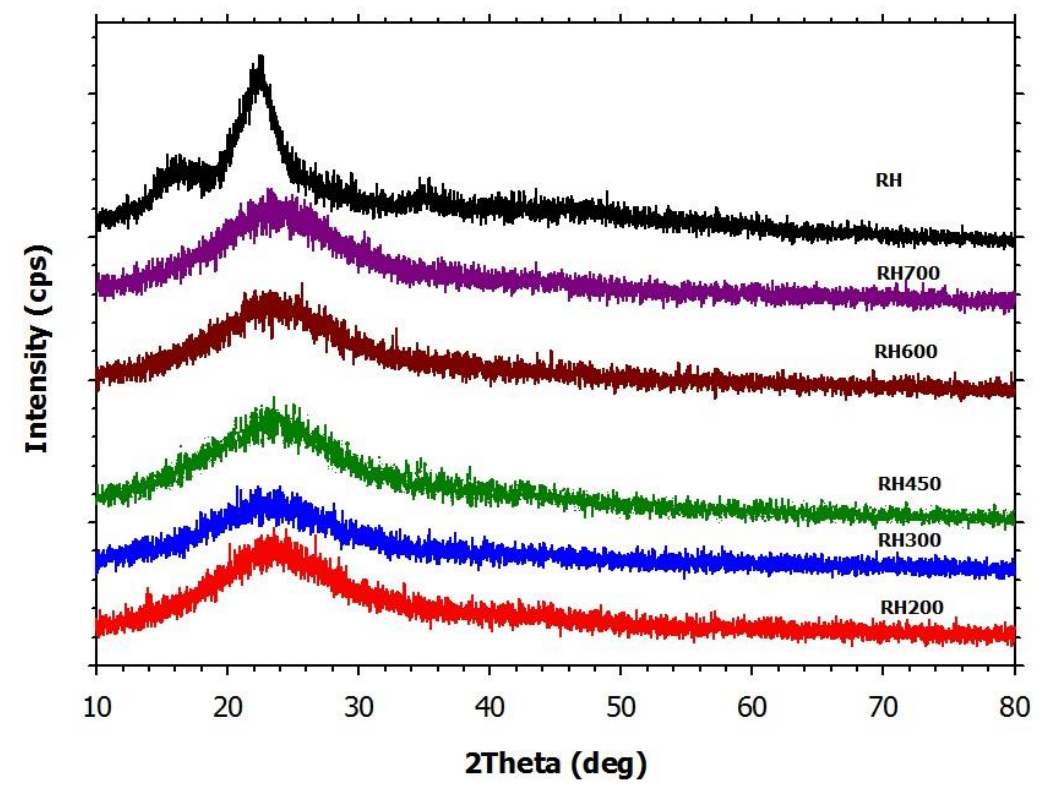




\subsubsection{Surface morphology}

To gain an insight on the morphology upon $\mathrm{RH}$ before and following MW pyrolysis and sulphonation, SEM analysis was done using S-3400N Hitachi. RH particle was inherently consisted of well-organized and corrugated outer wall. The outer surface was rough and it had spikes, as shown in Figure 6 (a). RH was supported by porous inner-layers and channels, as shown in Figure 6 (c). From the cross-sectional view, it can be observed that pores and channels were covered by the featureless layers. A randomly ordered and narrow pore structure can be clearly seen as zoomed in. See Figure 6 (d). The inner surface structure is different from the outer surface. The inner wall of RH had a lamella structure. This nature is similar as stated by [53]-[55]. RH is a brittle material. Thus, cracks on the side of Figure 6 (c) may due to grinding process prior to SEM analysis which caused particle to get ripped off.

After MW pyrolysis and sulphonation, cracks can be observed on the external wall surface of SRHC. This may be due to decomposition of organic material caused by the heat treatment from MW pyrolysis $[18,53]$. However, it is important to note that MW pyrolysis and sulphonation did not destruct the vascular completely. From Figure 7 (b), the outer wall remained, though, cracks can be seen. Meanwhile, porous structure is more obvious in the inner part of SRHC compared to RH feedstock due to thermal decomposition of organic material and acid treatment, as shown in Figure 7 (c). MW pyrolysis and sulphonation might have caused broadening and loosening of the naturally occurring pores. From the SEM images, the diameter of the pores is ranging from $19 \mu \mathrm{m}-92 \mu \mathrm{m}$, which is too big to be claimed as pores that resulted from MW pyrolysis. BET results show that pore diameters of SRHCs are around $\sim 4 \mathrm{~nm}$ on section 3.1.5. To avoid confusion, larger pores are called voids. Meanwhile, pores resulted from MW pyrolysis cannot really be seen from SEM images. The pores might be in the voids which hardly to be seen through SEM. Figure 8 (a) shows an image voids area of RH600 through EDX analysis. Pores inside the voids can be observed through this image (Figure 8 (b)). The SRHC had torn to pieces after the heat and chemical treatment. Stirring effect due to post sulphonation process could also contribute to this. 

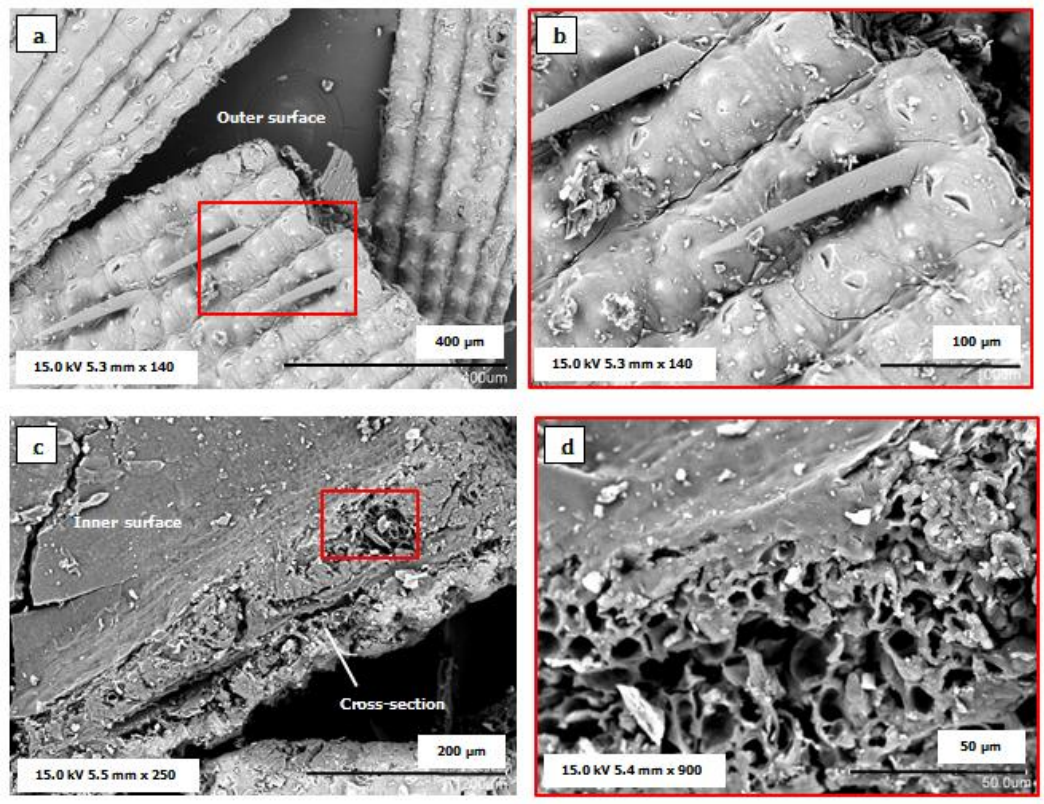

(b).

(c) and
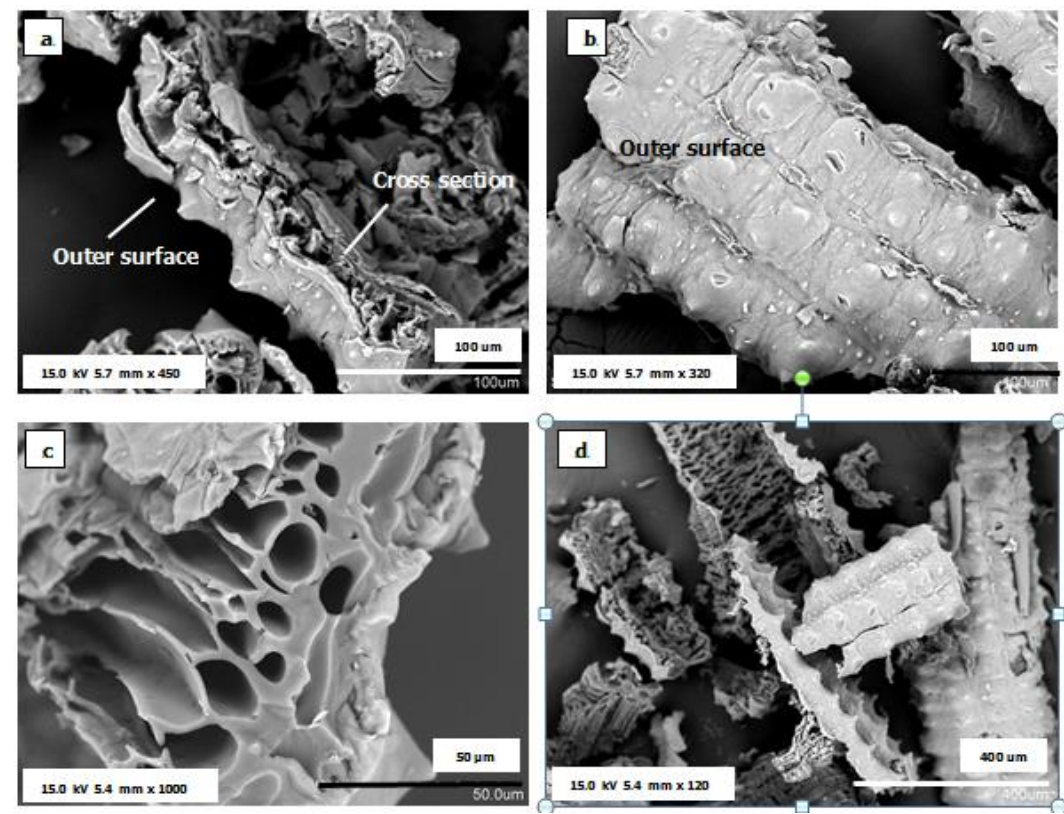
and (d).

Elemental composition on RH and SRHCs surfaces can be determined by coupling SEM with EDX analysis. Figure 8 shows two points were selected for EDX analysis; a point on the outer 437 surface and another point near the voids. EDX detected C, O, S, Si and a few other elements. 
However, only the compositions of $\mathrm{C}, \mathrm{O}, \mathrm{S}$, and $\mathrm{Si}$ will be discussed since other elements like $\mathrm{Au}$ and $\mathrm{Sr}$ may be due to the coating process prior to EDX analysis.

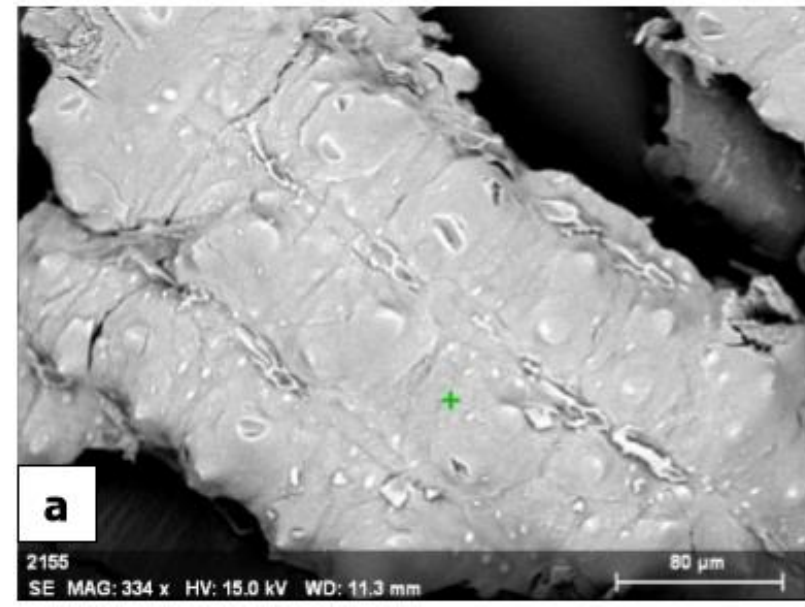

Figure 8:

(a) Point on an outer surface and (b) point on the inner surface of

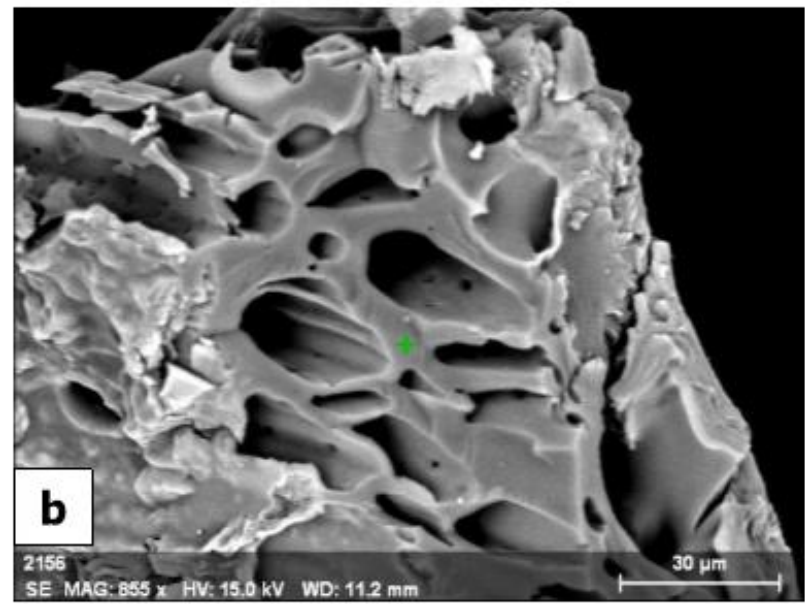

SHRC

Table 2 shows the results obtained from EDX for RH and SRHCs. The composition of $\mathrm{C}$ is higher on the inner surface as compared to the outer wall for raw $\mathrm{RH}$. Meanwhile, $\mathrm{O}$ and $\mathrm{Si}$ content on the outer surface are higher than the inner. High silica content appears to be at the outer epidermis of RH to provide strength to the $\mathrm{RH}$ [56]. No S element was detected on raw RH. Following MW pyrolysis and sulphonation, the trend of $\mathrm{C}, \mathrm{O}$ and $\mathrm{Si}$ is similar to raw $\mathrm{RH}$ as mentioned before. Si was present even after sulphonation which indicated that $\mathrm{Si}$ did not decompose even after subjected to MW pyrolysis and sulphonation. This reconfirms the results obtained from FTIR and XRD analysis.

$\mathrm{S}$ was detectable after sulphonation but only at the inner surface of the material, near the voids. No S element was detected in the outer wall of any SRHCs. RH450 did not show any S in Table 2.This is due to absence of $\mathrm{S}$ on the spot selected. $\mathrm{SO}_{3} \mathrm{H}$ density and FTIR results show that $\mathrm{S}$ is present on RH450. S spotted comes from sulphonation process, which suggests all $\mathrm{S}$ from EDX compositions belongs to the $\mathrm{SO}_{3} \mathrm{H}$. The results show that $\mathrm{SO}_{3} \mathrm{H}$ anchored at a carbonrich surface as opposed to silica, which is on the inner surface. This may be inferred as the $\mathrm{SO}_{3} \mathrm{H}$ favours carbon more than silica under the sulphonation condition used. Furthermore, the Scontent of RH600 was comparable to the S-content of a solid acid catalyst prepared via typical method [29]. Both silica and carbon are potential supports for the catalyst. $-\mathrm{SO}_{3} \mathrm{H}$ moiety covalently attached to $\mathrm{C}$. Meanwhile, $\mathrm{S}$ acts as support to the porous structure of $\mathrm{C}$. 
Table 2: Elemental compositions of RH and SRHCs using EDX

\begin{tabular}{ccccccccc}
\hline \multirow{2}{*}{ Sample } & \multicolumn{2}{c}{ C } & \multicolumn{2}{c}{ O } & \multicolumn{2}{c}{ S } & \multicolumn{2}{c}{ Si } \\
\cline { 2 - 8 } & a & b & a & b & a & b & a & b \\
\hline RH & 14.96 & 44.36 & 47.85 & 21.35 & - & - & 18.46 & 1.95 \\
RH200 & 20.24 & 58.12 & 31.59 & 32.64 & - & 1.65 & 21.93 & 1.05 \\
RH300 & 9.99 & 58.13 & 43.53 & 26.56 & - & 1.38 & 25.86 & 0.70 \\
RH450 & 24.42 & 43.01 & 45.87 & 28.72 & - & - & 13.87 & 7.81 \\
RH600 & 11.67 & 51.28 & 41.39 & 19.83 & - & 3.15 & 23.02 & 2.33 \\
RH700 & 12.91 & 25.31 & 39.82 & 14.77 & - & 8.19 & 23.94 & 4.06 \\
\hline
\end{tabular}

464

465

466

467

468

469

a referred to spot at outer surface, $\mathbf{b}$ referred to a spot at inner surface near honeycomb structure. Composition is in wt.\%.

\subsubsection{Surface area}

In order to understand structural changes on $\mathrm{RH}, \mathrm{BET}$ analysis had been conducted using ASAP 2020, Micromeritics. Specific area of RH and SRHCs were determined using the BET method, meanwhile pore diameter and pore volume were determined using $\mathrm{BJH}$ desorption method. $\mathrm{RH}$ had a surface area of $11.52 \mathrm{~m}^{2} / \mathrm{g}$ and it showed mesoporosity with a pore size of $4.15 \mathrm{~nm}$. As for SRHCS, all showed mesoporosity with pore diameter ranging from $3.89 \mathrm{~nm}$ to $5.41 \mathrm{~nm}$, as shown in Table 3. No correlation was observed between power level and surface area. However, RH600, RH200 and RH300 showed an increase of 20.6\%, 17.6\%, $11.3 \%$, respectively, in surface area, after MW pyrolysis and sulphonation. RH450 and RH700 showed drastic reduction of surface area after the two processes. Most likely the reduction of the surface area was associated with the collapse of the voids in the sample as supported by their low pore volumes. This may imply that certain MW powers induce the vibration of the inner pore walls that causing to collapse. Further studies are needed to ascertain this speculation, especially on the carbon and silica parts of the sample. All SHRCs showed an increase in pore volume after MW pyrolysis and sulphonation, with RH200 and RH600 show the highest pore volume among all SRHCs. RH600 was used for further characterization studies as it has shown the highest reactivity on esterification reaction.

The isotherms of SRHCs show similar results. See supplementary data. Figure 9 shows $\mathrm{N}_{2}$ absorption-desorption isotherms of RH and RH600 to represent SRHCs. The upper line of each loop is referring to $\mathrm{N}_{2}$ desorption and the lower line is the traced of $\mathrm{N}_{2}$ adsorption. $\mathrm{RH}$ shows lower nitrogen adsorption and desorption capacity which indicates the lower porosity of RH. Meanwhile, RH600 shows a desorption shoulder at $0.42 \mathrm{P} / \mathrm{P}_{0}$ and lower closure points. $\mathrm{N}_{2}$ adsorption increase remarkably after $0.42 \mathrm{P} / \mathrm{P}_{0}$, where pore condensation takes place. Plateau is not observed at a 
high $\mathrm{P} / \mathrm{P}_{0}$ for $\mathrm{RH} 600$. These indicate $\mathrm{RH} 600$ is a porous material. The characteristics of the loop suggests that RH600 isotherm is of type II with a hysteresis loop of type H3 loop according to IUPAC. Theoretically, isotherm type II is assigned to a non-porous material. However, it is also applicable to a porous solid [18]. This pseudo-type II isotherm is associated with the low degree of pore curvature and non-rigidity of the aggregate structure. The difference between RH and RH600 shows that the opening of pores happened after MW pyrolysis.

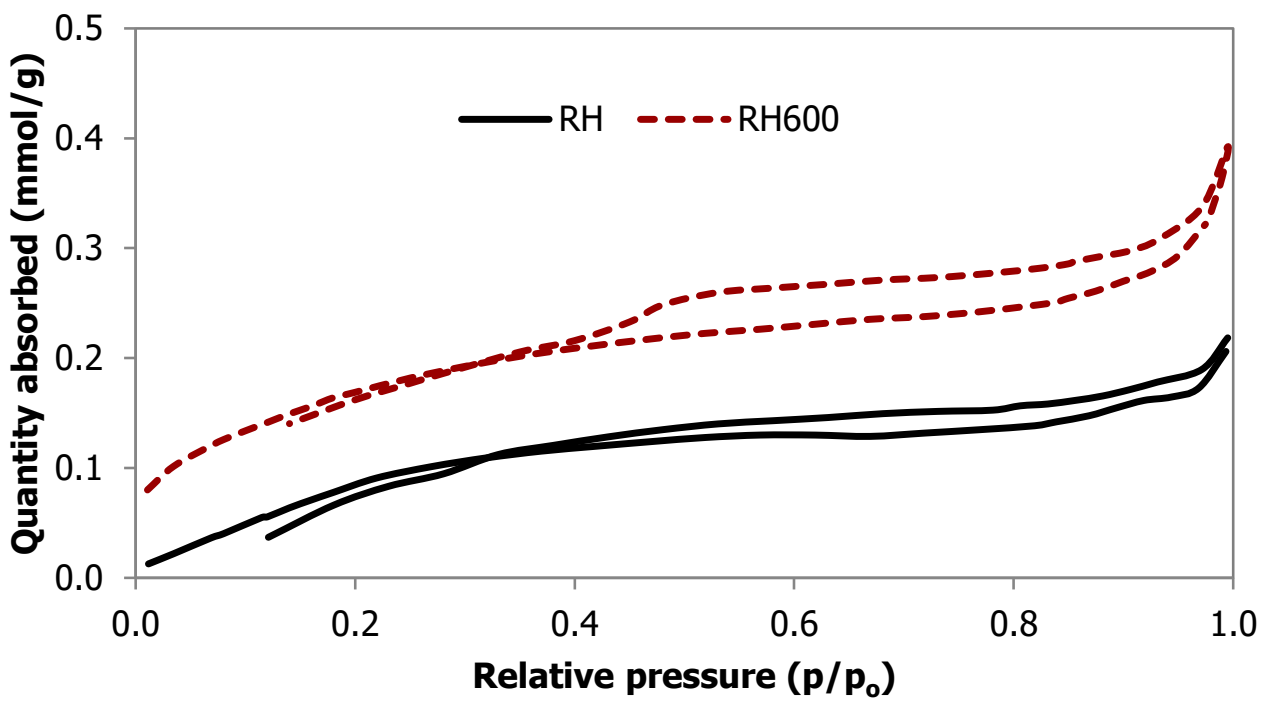

\section{Figure 9: $\quad$ Nitrogen adsorption-desorption of RH and RH600}

\subsection{Catalytic activity of SRHC by esterification of oleic acid}

Figure 10 shows the comparison of activity of SRHCs and $\mathrm{H}_{2} \mathrm{SO}_{4}$ on esterification of oleic acid and methanol in term of methyl oleate produced. The points represent concentrations meanwhile the lines are the best curve fit using 'ligand binding, one site saturation + nonspecific' model. The best curve fitting was determined by using model available in Sigma Plot 10.0 software. Value for error bars was taken from the average of the standard deviations obtained from three runs of esterification reactions using RH700. The average standard deviation (SD) calculated was 0.014 $\mathrm{mol} / \mathrm{L}$ and used as the standard deviation of the population to represent SD for all data points. The standard deviation was low. Statistically, results obtained from this experiment are reliable. Figure 10 shows an increase in concentration of methyl oleate over time. Curve fit remained plateau starting from the $1^{\text {st }} \mathrm{h}$ of reaction for $\mathrm{H}_{2} \mathrm{SO}_{4}$. As for SHRCs, concentration of methyl oleate at the $10^{\text {th }}$ to $12^{\text {th }} \mathrm{h}$ of reaction time shows only slight increased, almost plateau. This suggests 
511 that the reaction catalyzed by SRHCs already reached equilibrium at the $10^{\text {th }} \mathrm{h}$. Equilibrium is a 512 state where the rate of the forward reaction is equal to the rate of backward reaction. Thus, no

513 further change in the concentration of both product and reactants is observed. Compare to $\mathrm{H}_{2} \mathrm{SO}_{4}$, 514 the reaction catalyzed by $\mathrm{H}_{2} \mathrm{SO}_{4}$ reached equilibrium at the $1^{\text {st }} \mathrm{h}$ of reaction, approximately $10 \mathrm{~h}$ 515 faster than SRHCs. The fast formation of $\mathrm{MO}$ by $\mathrm{H}_{2} \mathrm{SO}_{4}$ was also reported by other researchers $516[29,31]$.

All SRHCs had comparable activities. Best curve fits in Figure 10 shows that the reaction at similar reaction condition will eventually reach the equilibrium or endpoint regardless of catalyst used. This is in agreement with the catalysis theory $[29,55,56]$. According to Levenspiel, catalyst did not determine the equilibrium constant or endpoint of the product, rather equilibrium is governed by thermodynamic. The significant different shown in Figure 10 was the initial formation rate of $\mathrm{H}_{2} \mathrm{SO}_{4}$ as compared to SRHCs. Table 3 shows the initial formation rate of reactions for SRHCs and $\mathrm{H}_{2} \mathrm{SO}_{4}$. The initial formation rate was calculated by determining the gradient of the plot of concentration versus time evaluated at $\mathrm{t}=0[29,56]$. The initial formation rate of $\mathrm{H}_{2} \mathrm{SO}_{4}$ is 3-4 times higher than SRHCs, which is $20.03 \mathrm{mmol} \cdot \mathrm{L}^{-1} \cdot \mathrm{min}^{-1}$. Meanwhile, RH600 shows the 526 highest initial formation rate among SRHCs and it has an initial formation rate of $6.33 \mathrm{mmol} . \mathrm{L}$ $527{ }^{1} \cdot \mathrm{min}^{-1}$. The order of the initial formation rate for SRHCs is as follow: RH600 > RH2O0 > RH700 $528>\mathrm{RH} 450>\mathrm{RH} 300$. No trend is observed between pyrolysis power and the rate.

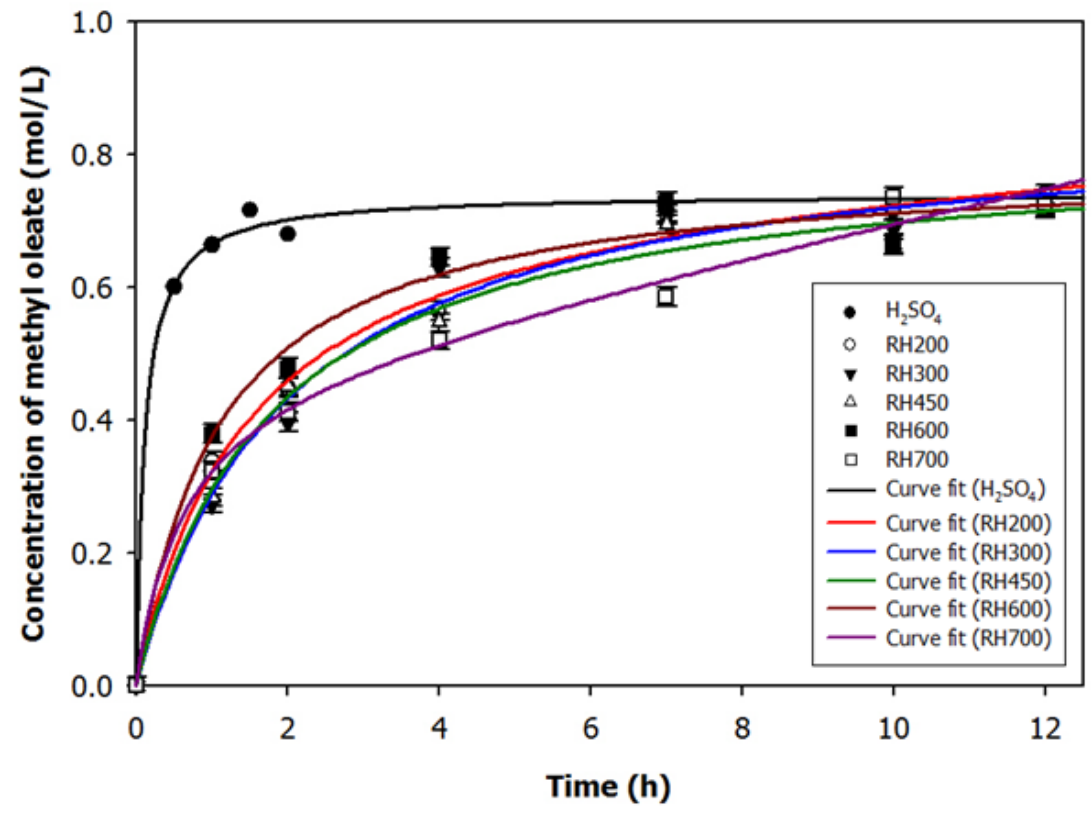
at $60^{\circ} \mathrm{C}$ for $12 \mathrm{~h}$ reaction time 
Reaction catalyzed by $\mathrm{H}_{2} \mathrm{SO}_{4}$ was expected to be fast because of the homogeneity of $\mathrm{H}_{2} \mathrm{SO}_{4}$ with the reactants. Unlike heterogeneous catalyst like SRHC, the rate is influenced by several factors [58]. Among the factors that might slow the rate are surface kinetics and pore diffusion $[55,56]$. To relationally evaluate the activity of SRHCS, the initial formation rates of SRHCs were also compared to sugar catalyst, a heterogeneous acid catalyst. Janaun ... reported that sugar catalyst has an initial formation rate of $4.03 \mathrm{mmol} . \mathrm{L}^{-1} \mathrm{~min}^{-1}$, which is even lower than RH300. To gain further information on reactivity of SRHCS, SRHC was compared with reaction without the presence of a catalyst. Using RH600 for comparison, RH600 successfully speeded up the reaction approximately 49 times faster than reaction with no catalyst. With this information, SRHCs show excellent activity in term of formation of methyl oleate.

Table 3 shows the yield of methyl oleate obtained at the $12^{\text {th }} \mathrm{h}$. RH600 shows the highest yield at the $12^{\text {th }} \mathrm{h}$, followed by $\mathrm{RH} 200, \mathrm{RH} 450, \mathrm{RH} 300$ and $\mathrm{RH} 700$. The yield obtained by SRHCS exceeded the yield of methyl oleate by $\mathrm{H}_{2} \mathrm{SO}_{4}$ as well as yield obtained by sugar catalyst reported by Janaun [29]. The high yield may attribute to the increase in pore size. The larger pore size will enable fast diffusion of large molecules reactants to enter into the active sites, as well as, large molecule products to leave the active sites $[31,56]$. SRHCs showed mesoporosity. However, RH600 and RH200 have larger pore volume among SRHCs, thus larger pore size. The correlation between yield and surface area can be observed. Yield increases as the surface area of the catalyst increases. High surface area denotes high porosity. According to Fogler, high surface area provides more area for high rate of rate of reaction [58]. This explained the high initial formation rate and yield of RH600 and RH200. RH600 shows an excellent performance with initial formation rate of $6.33 \mathrm{mmol} . \mathrm{L}^{-1} \cdot \mathrm{min}^{-1}$ and $97.19 \%$ yield of methyl oleate. The performance was attributed to the high surface area and high $\mathrm{SO}_{3} \mathrm{H}$ density of $\mathrm{RH} 600$, which were $14.52 \mathrm{~m}^{2} / \mathrm{g}$ and 0.86

Table 3: Comparison of characteristics and activity of SRHCs with other acid catalysts

\begin{tabular}{|c|c|c|c|c|c|}
\hline \multirow[t]{2}{*}{ Catalyst } & \multicolumn{3}{|c|}{$\mathbf{N}_{2}$ adsorption ${ }^{d}$} & \multirow{2}{*}{$\begin{array}{l}\text { Yield } \\
(\%)\end{array}$} & \multirow{2}{*}{$\begin{array}{c}\text { Initial formation } \\
\text { rate }\left(\mathrm{mmol}^{-1} \mathrm{~L}^{-1} \cdot \mathrm{min}^{-}\right. \\
\left.{ }^{1}\right)\end{array}$} \\
\hline & S.A & P.D & P.V & & \\
\hline $\begin{array}{l}\mathrm{H}_{2} \mathrm{SO}_{4}{ }^{\mathrm{a}} \\
\mathrm{RH} 200^{\mathrm{a}}\end{array}$ & $\begin{array}{c}- \\
13.56\end{array}$ & $\begin{array}{c}- \\
4.20\end{array}$ & $\begin{array}{c}- \\
0.015\end{array}$ & $\begin{array}{l}89.27 \\
97.18\end{array}$ & $\begin{array}{c}20.03 \\
5.63\end{array}$ \\
\hline
\end{tabular}




\begin{tabular}{lccccc} 
RH300 & 13.00 & 3.86 & 0.009 & 94.02 & 4.57 \\
RH450 $_{\text {RH600 }}^{a}$ & 8.02 & 4.26 & 0.009 & 94.76 & 4.73 \\
RH700 & 14.52 & 4.08 & 0.015 & 97.19 & 6.33 \\
No catalyst [59] & 5.99 & 5.41 & 0.009 & 91.72 & 5.38 \\
Sugar catalyst [29] & - & - & - & $8.98^{\mathrm{b}}$ & 0.13 \\
\hline
\end{tabular}

Denotes this work

$561{ }^{b}$ Yield at $24^{\text {th }} \mathrm{h}$. Esterification of oleic acid with methanol at $60^{\circ} \mathrm{C}$, molar ratio $10: 1,3$ wt. $\%$ 562 catalyst loading.

$563{ }^{c}$ Yield at $12^{\text {th }} \mathrm{h}$. Esterification of oleic acid with methanol at $80^{\circ} \mathrm{C}$, molar ratio $10: 1,3$ wt. $\%$ 564 catalyst loading. The catalyst was synthesized using conventional pyrolysis and sulphonated in $\mathrm{N}_{2}$ 565 atmosphere.

$566{ }^{d}$ BET surface area $\left(\mathrm{m}^{2} / \mathrm{g}\right)$; P.D is pore diameter $(\mathrm{nm}) ;$ P.V is pore volume $\left(\mathrm{cm}^{3} / \mathrm{g}\right)$

567

568

\subsection{Reusability of SRHC}

569 One of the advantages of heterogeneous catalyst over homogenous catalyst is ease of separation.

570 The catalyst can be recovered, washed and reused. Figure 11 shows the reusability performance 571 of RH600 drop almost gradually when reused. The conversion of oleic acid reduced from $97.19 \%$ 572 to $82.90 \%, 70.18 \%$ and $52.83 \%$ upon reused. First reused showed a performance dropped off $57317.2 \%$ from fresh. Second reuse shows $18.1 \%$ less conversion out of total conversion of oleic 574 acid from the first reused. Reaction using the third reused was able to convert only $52.83 \%$ of 575 oleic acid into methyl oleate. The performance dropped $32.8 \%$ from the second reused. The 576 gradual decrease in catalyst performance after every reuse cycle was coincided with the results 577 obtained by [58-61]. Further studies had been conducted by the researchers. They concluded 578 that, the declination of catalytic performance might due to leaching of $-\mathrm{SO}_{3} \mathrm{H}$. Leaching of $-\mathrm{SO}_{3} \mathrm{H}$ 579 might be due to washing of catalyst with methanol $[58,62]$. Although methanol can dissolve fatty 580 acid bounded to the catalyst, however, methanol washing leads to reduction of catalytic 581 performance. This is because methanol will react sulphonic acid from the catalyst to form methyl 582 sulphonate $[58,63]$. Resulting, reduction of functional group and its performance happened. 


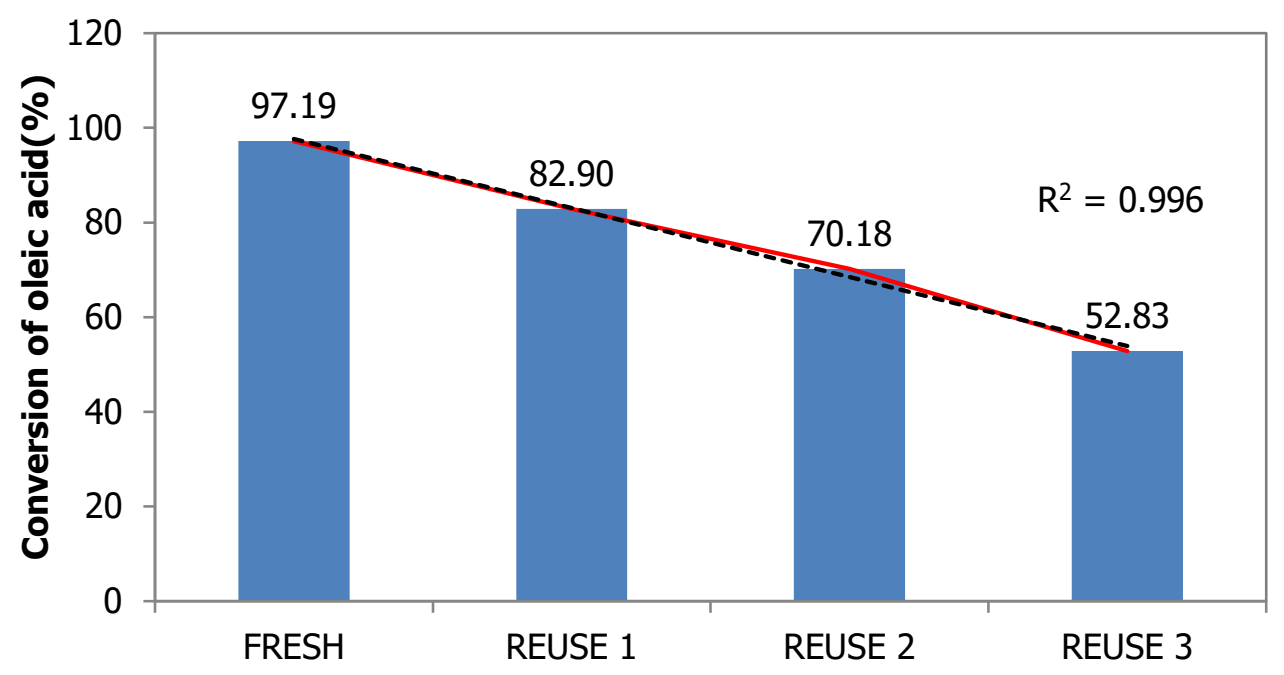

\section{Figure 11: Reusability performance of RH600}

\subsection{Esterification of oil from POME using SRHC}

Table 4 shows the physicochemical properties of the recovered oil from POME. The properties were determined according to procedure in section 2.3. Generally, recovered oil has a high FFA value which can be classified as low-grade oil for biodiesel production.

Table 4: Properties of recovered oil from POME

\begin{tabular}{lcc}
\hline \multicolumn{2}{c}{ Physicochemical properties } & SD (\%) \\
\hline Density $(\mathrm{g} / \mathrm{mL})\left(30^{\circ} \mathrm{C}\right)$ & 0.872 & 0.20 \\
Saponification value & 226.5 & 2.74 \\
Acid value $\left(\mathrm{mg}\right.$ of $\left.\mathrm{KOH} . \mathrm{g}^{-1}\right)$ & 32.1 & 1.33 \\
Free fatty acid $(\mathrm{FFA})(\%)$ & 16.1 & \\
\hline
\end{tabular}

Catalytic performance of RH600 was tested through in-situ esterification and transesterification reaction of oil recovered from POME. The reaction condition used was different from the esterification of oleic acid due to the properties of the palm oil. Recovered oil has a very low miscibility with alcohol. Besides, it is a heavy compound. Thus, higher molar ratio was used in this reaction in order to reduce mass transfer limiting factor [66].

The recovered oil has high acid value which is $32.1 \mathrm{mg}$ of $\mathrm{KOH} . \mathrm{g}^{-1}$. The performance of RH600 was determined by its ability to reduce the AV through esterification reaction. The conversion of FFA into FAME was calculated using Equation 2. Table 4 shows the conversion of 


\begin{tabular}{ccccc}
\hline Replication & Acid Value & $\begin{array}{c}\text { Conversion } \\
\mathbf{( \% )}\end{array}$ & $\begin{array}{c}\text { Standard } \\
\text { deviation }\end{array}$ & $\begin{array}{c}\text { Relative standard } \\
\text { deviation (\%) }\end{array}$ \\
\hline 1 & 5.0 & 84.6 & & \\
2 & 3.3 & 89.6 & 2.57 & 2.94 \\
3 & 3.9 & 87.8 & & \\
\hline \multicolumn{2}{l}{ Average conversion (\%) } & $\mathbf{8 7 . 3}$ & & \\
\hline
\end{tabular}

FFA into FAME. Esterification of recovered oil had successfully converted $87.3 \% \pm 2.57$ of FFA had been into FAME under the reaction condition used. This proves that this catalyst is also capable of converting FFA from POME into biodiesel.

Table 1: Esterification of oil recovered from POME
605

606

607

608

609

610

611

612

613

614

615

616

617

618

619

620

621

622

623

624

625

626

627

\section{Conclusions}

Carbon-silica hybrid based acid catalysts derived from RH were successfully synthesized using MW. The elemental compositions determined by elemental analyzer showed an increase in S (17.2 to 18.5 times higher) content after MW sulphonation. The calculated $-\mathrm{SO}_{3} \mathrm{H}$ density of SRHCs were between $0.80-0.86 \mathrm{mmol} / \mathrm{g}$. The FTIR results for all SRHCs further proved the presence of $-\mathrm{SO}_{3} \mathrm{H}$ group on the catalysts by the appearance of peak at $1035 \mathrm{~cm}^{-1}$ which corresponded to $\mathrm{O}=\mathrm{S}=\mathrm{O}$ stretching of $-\mathrm{SO}_{3} \mathrm{H}$ group. Besides, FTIR detected that peak related to silica $\left(788 \mathrm{~cm}^{-1}\right)$ remained even after MW pyrolysis and sulphonation. The FTIR results suggested that silica was not decomposed though subjected to heat and acid treatment. XRD results showed that all SRHCs have an amorphous structure. Through SEM magnification, it was observed that MW pyrolysis and sulphonation caused broadening of the RH voids and also formation of pores. The outer surface of the $\mathrm{RH}$, where high $\mathrm{S}$ content was detected through EDX analysis, was cracked after the heat and acid treatment, but not destructed completely. Meanwhile, the inner surface, where more pores were observed, contained high $\mathrm{C}$ content. Thus, it was assumed that silica provides support for the fragile porous $\mathrm{C}$ structure. BET analysis results showed SRHCs are all mesoporous with pore diameter ranging from $3.89 \mathrm{~nm}$ to $5.41 \mathrm{~nm}$. RH600 had the highest specific surface area among SRHCs. All SRHCs showed high catalytic activity for esterification of oleic acid with methanol under stated reaction condition. RH600 had the highest initial formation rate of 6.33 mmol. $L^{-1} \cdot \mathrm{min}^{-1}$ followed by, RH200, RH700, RH450 and RH300, with initial formation rates of $5.63,5.38,4.73$, and $4.57 \mathrm{mmol}^{-1} \cdot \mathrm{min}^{-1}$, respectively. Reaction catalyzed by SRHC reached equilibrium at the 10 th reaction time. The yield obtained by reaction catalyzed by SRHC 
exceeded yield obtained using $\mathrm{H}_{2} \mathrm{SO}_{4}$. RH600 had the highest esters yield, which was $97.19 \%$. Meanwhile, ester yield obtained from the reaction catalyzed by $\mathrm{H}_{2} \mathrm{SO}_{4}$ was $89.27 \%$ only. Reusability of catalyst showed gradual dropped in yield for every reused. The declination of catalytic performance might due to leaching of $-\mathrm{SO}_{3} \mathrm{H}$, due to washing of catalyst with methanol.

In conclusion, carbon-silica hybrid based acid catalysts derived from $\mathrm{RH}$ had been successfully synthesized. The catalysts possessed desirable properties like high reactivity, high thermal stability, easy to be functionalized or have an amorphous structure and porous material, that is suitable for biodiesel production.

\section{Acknowledgements}

This work was supported by Geran Kolaborasi (GKP 0009); UMS Graduate Research Grant; and Newton Fund by British Council.

\section{References}

[1] S. Mekhilef, S. Siga, and R. Saidur, "A review on palm oil biodiesel as a source of renewable fuel," Renewable and Sustainable Energy Reviews, vol. 15, no. 4, pp. 1937-1949, May 2011, doi: 10.1016/j.rser.2010.12.012.

[2] N. H. Zainal et al., "Reduction of POME final discharge residual using activated bioadsorbent from oil palm kernel shell," Journal of Cleaner Production, vol. 182, pp. 830-837, May 2018, doi: 10.1016/j.jclepro.2018.02.110.

[3] M. A. Shavandi, Z. Haddadian, M. H. S. Ismail, and N. Abdullah, "Continuous metal and residual oil removal from palm oil mill effluent using natural zeolite-packed column," Journal of the Taiwan Institute of Chemical Engineers, vol. 43, no. 6, pp. 934-941, Nov. 2012, doi: 10.1016/j.jtice.2012.07.001.

[4] G. D. Najafpour, A. A. L. Zinatizadeh, A. R. Mohamed, M. Hasnain Isa, and H. Nasrollahzadeh, "High-rate anaerobic digestion of palm oil mill effluent in an upflow anaerobic sludge-fixed film bioreactor," Process Biochemistry, vol. 41, no. 2, pp. 370-379, Feb. 2006, doi: 10.1016/j.procbio.2005.06.031.

[5] Y. Ahmed, Z. Yaakob, P. Akhtar, and K. Sopian, "Production of biogas and performance evaluation of existing treatment processes in palm oil mill effluent (POME)," Renewable and Sustainable Energy Reviews, vol. 42, pp. 1260-1278, Feb. 2015, doi: 10.1016/j.rser.2014.10.073. 
658 [6] S. Ibrahim, H.-M. Ang, and S. Wang, "Removal of emulsified food and mineral oils from 659 wastewater using surfactant modified barley straw," Bioresource Technology, vol. 100, no. 23, pp. 5744660 5749, Dec. 2009, doi: 10.1016/j.biortech.2009.06.070.

661 [7] S. R. P. Primandari, M. Masita, and A. B. Mohamad, "Characteristics of Residual Oil Extracted 662 from Palm Oil Mill Effluent (POME)," 2013, 2013.

663 [8] A. M. A. Pintor, V. J. P. Vilar, C. M. S. Botelho, and R. A. R. Boaventura, "Oil and grease removal 664 from wastewaters: Sorption treatment as an alternative to state-of-the-art technologies. A critical 665 review," Chemical Engineering Journal, vol. 297, pp. 229-255, Aug. 2016, doi: 10.1016/j.cej.2016.03.121.

666 [9] Rosalam Sarbatly, Duduku Krishnaiah, and Zykamilia Kamin, "A review of polymer nanofibres by 667 electrospinning and their application in oil-water separation for cleaning up marine oil spills," Marine 668 Pollution Bulletin, no. 106, pp. 8-16, 2016, doi: 10.1016/j.marpolbul.2016.03.037.

669 [10] C. H. Chung, J. Janaun, V. Semilin, and W. S. Balan, "Recovery of residual oil from palm oil mill 670 effluent using polypropylene nanofiber: a field trial," MATTER: International Journal of Science and 671 Technology, vol. 3, no. 2, Oct. 2017, Accessed: Sep. 02, 2018. [Online]. Available:

672 https://www.grdspublishing.org/index.php/matter/article/view/703.

673 [11] V. Semilin, B. Albert, and J. Janaun, "Effect of process parameters on removal of oil from pome 674 using polypropylene micro/nanofiber," MATTER: International Journal of Science and Technology, vol. 3, 675 no. 3, 2017, Accessed: Mar. 24, 2020. [Online]. Available:

676 https://grdspublishing.org/index.php/matter/article/view/975.

677 [12] W. S. Balan, J. Janaun, and N. J. Siambun, "Conversion of oil recovered from palm oil mill 678 effluent (pome) into biodiesel using electrolysed carbon catalyst," MATTER: International Journal of 679 Science and Technology, vol. 3, no. 2, Oct. 2017, Accessed: Jun. 19, 2018. [Online]. Available: 680 https://grdspublishing.org/index.php/matter/article/view/702.

681 [13] J. Janaun and N. Ellis, "Perspectives on biodiesel as a sustainable fuel," Renewable and 682 Sustainable Energy Reviews, vol. 14, no. 4, pp. 1312-1320, May 2010, doi: 10.1016/j.rser.2009.12.011.

683 [14] M. Okamura et al., "Acid-Catalyzed Reactions on Flexible Polycyclic Aromatic Carbon in 684 Amorphous Carbon," Chem. Mater., vol. 18, no. 13, pp. 3039-3045, Jun. 2006, doi: 10.1021/cm0605623.

685 [15] A. Takagaki et al., "Esterification of higher fatty acids by a novel strong solid acid," Catalysis 686 Today, vol. 116, no. 2, pp. 157-161, Aug. 2006, doi: 10.1016/j.cattod.2006.01.037.

687 [16] M. Toda et al., "Green chemistry: Biodiesel made with sugar catalyst," Nature, vol. 438, no. 688 7065, pp. 178-178, Nov. 2005, doi: 10.1038/438178a.

689 [17] K. Nakajima and M. Hara, "Amorphous Carbon with SO3H Groups as a Solid Brønsted Acid 690 Catalyst," ACS Catal., vol. 2, no. 7, pp. 1296-1304, Jul. 2012, doi: 10.1021/cs300103k. 
[18] D. Touhami, Z. Zhu, W. S. Balan, J. Janaun, S. Haywood, and S. Zein, "Characterization of rice husk-based catalyst prepared via conventional and microwave carbonisation," Journal of Environmental Chemical Engineering, vol. 5, no. 3, pp. 2388-2394, Jun. 2017, doi: 10.1016/j.jece.2017.04.020.

[19] R. A. Heikka, K. T. Immonen, P. O. Minkkinen, E. Y. O. Paatero, and T. O. Salmi, "Determination of acid value, hydroxyl value and water content in reactions between dicarboxylic acids and diols using near-infrared spectroscopy and non-linear partial least squares regression," Analytica Chimica Acta, vol. 349, no. 1, pp. 287-294, Aug. 1997, doi: 10.1016/S0003-2670(97)00215-8.

[20] B.-J. Lin and W.-H. Chen, "Sugarcane Bagasse Pyrolysis in a Carbon Dioxide Atmosphere with Conventional and Microwave-Assisted Heating," Front. Energy Res., vol. 3, 2015, doi: 10.3389/fenrg.2015.00004.

[21] X. Zhao, W. Wang, H. Liu, C. Ma, and Z. Song, "Microwave pyrolysis of wheat straw: Product distribution and generation mechanism," Bioresource Technology, vol. 158, pp. 278-285, Apr. 2014, doi: 10.1016/j.biortech.2014.01.094.

[22] A. Takagaki et al., "Esterification of higher fatty acids by a novel strong solid acid," Catalysis Today, vol. 116, no. 2, pp. 157-161, Aug. 2006, doi: 10.1016/j.cattod.2006.01.037.

[23] J. A. Melero, L. F. Bautista, G. Morales, J. Iglesias, and R. Sánchez-Vázquez, "Biodiesel production from crude palm oil using sulfonic acid-modified mesostructured catalysts," Chemical Engineering Journal, vol. 161, no. 3, pp. 323-331, Jul. 2010, doi: 10.1016/j.cej.2009.12.037.

[24] R. Sheikh, M.-S. Choi, J.-S. Im, and Y.-H. Park, "Study on the solid acid catalysts in biodiesel production from high acid value oil," Journal of Industrial and Engineering Chemistry, vol. 19, no. 4, pp. 1413-1419, Jul. 2013, doi: 10.1016/j.jiec.2013.01.005.

[25] M. I. Al-Wabel, A. Al-Omran, A. H. El-Naggar, M. Nadeem, and A. R. A. Usman, "Pyrolysis temperature induced changes in characteristics and chemical composition of biochar produced from conocarpus wastes," Bioresource Technology, vol. 131, pp. 374-379, Mar. 2013, doi: 10.1016/j.biortech.2012.12.165.

[26] W. Song and M. Guo, "Quality variations of poultry litter biochar generated at different pyrolysis temperatures," Journal of Analytical and Applied Pyrolysis, vol. 94, pp. 138-145, Mar. 2012, doi: 10.1016/j.jaap.2011.11.018.

[27] N. Worasuwannarak, T. Sonobe, and W. Tanthapanichakoon, "Pyrolysis behaviors of rice straw, rice husk, and corncob by TG-MS technique," Journal of Analytical and Applied Pyrolysis, vol. 78, no. 2, pp. 265-271, Mar. 2007, doi: 10.1016/j.jaap.2006.08.002.

[28] T. Liu, Z. Li, W. Li, C. Shi, and Y. Wang, "Preparation and characterization of biomass carbonbased solid acid catalyst for the esterification of oleic acid with methanol," Bioresource Technology, vol. 133, pp. 618-621, Apr. 2013, doi: 10.1016/j.biortech.2013.01.163. 
[29] J. A. B. Janaun, "Development of sulfonated carbon catalysts for integrated biodiesel production," 2012, Accessed: May 18, 2015. [Online]. Available:

https://circle.ubc.ca/handle/2429/43140.

[30] X. Mo, E. Lotero, C. Lu, Y. Liu, and J. G. Goodwin, "A Novel Sulfonated Carbon Composite Solid Acid Catalyst for Biodiesel Synthesis," Catal Lett, vol. 123, no. 1-2, pp. 1-6, Mar. 2008, doi: 10.1007/s10562-008-9456-y.

[31] L. Peng et al., "Preparation of sulfonated ordered mesoporous carbon and its use for the esterification of fatty acids," Catalysis Today, vol. 150, no. 1-2, pp. 140-146, Feb. 2010, doi: 10.1016/j.cattod.2009.07.066.

[32] L. Shi et al., "Functional rice husk as reductant and support to prepare as-burnt Cu-ZnO based catalysts applied in low-temperature methanol synthesis," Catalysis Communications, vol. 89, pp. 1-3, Jan. 2017, doi: 10.1016/j.catcom.2016.10.011.

[33] R. V. Sharma, A. K. R. Somidi, and A. K. Dalai, "Preparation and Properties Evaluation of Biolubricants Derived from Canola Oil and Canola Biodiesel," J. Agric. Food Chem., vol. 63, no. 12, pp. 3235-3242, Apr. 2015, doi: 10.1021/jf505825k.

[34] S. Hu, J. Xiang, L. Sun, M. Xu, J. Qiu, and P. Fu, "Characterization of char from rapid pyrolysis of rice husk," Fuel Processing Technology, vol. 89, no. 11, pp. 1096-1105, Nov. 2008, doi: 10.1016/j.fuproc.2008.05.001.

[35] S. Hu, J. Xiang, L. Sun, M. Xu, J. Qiu, and P. Fu, "Characterization of char from rapid pyrolysis of rice husk," Fuel Processing Technology, vol. 89, no. 11, pp. 1096-1105, Nov. 2008, doi: 10.1016/j.fuproc.2008.05.001.

[36] R. K. Sharma, J. B. Wooten, V. L. Baliga, X. Lin, W. Geoffrey Chan, and M. R. Hajaligol, "Characterization of chars from pyrolysis of lignin," Fuel, vol. 83, no. 11, pp. 1469-1482, Aug. 2004, doi: 10.1016/j.fuel.2003.11.015.

[37] T.-H. Liou and S.-J. Wu, "Characteristics of microporous/mesoporous carbons prepared from rice husk under base- and acid-treated conditions," Journal of Hazardous Materials, vol. 171, no. 1, pp. 693703, Nov. 2009, doi: 10.1016/j.jhazmat.2009.06.056.

[38] N. Johar, I. Ahmad, and A. Dufresne, "Extraction, preparation and characterization of cellulose fibres and nanocrystals from rice husk," Industrial Crops and Products, vol. 37, no. 1, pp. 93-99, May 2012, doi: 10.1016/j.indcrop.2011.12.016.

[39] X. Liang, M. Zeng, and C. Qi, "One-step synthesis of carbon functionalized with sulfonic acid groups using hydrothermal carbonization," Carbon, vol. 48, no. 6, pp. 1844-1848, May 2010, doi: 10.1016/j.carbon.2010.01.030. 
[40] W. W. Mar and E. Somsook, "Sulfonic-Functionalized Carbon Catalyst for Esterification of High Free Fatty Acid," Procedia Engineering, vol. 32, pp. 212-218, Jan. 2012, doi: 10.1016/j.proeng.2012.01.1259.

[41] I. Kim, J. Kim, and D. Lee, "Sulfonic acid functionalized deoxycellulose catalysts for glycerol acetylation to fuel additives," Applied Catalysis A: General, vol. 482, pp. 31-37, Jul. 2014, doi: 10.1016/j.apcata.2014.05.018.

[42] Md. S. Islam, N. Kao, S. N. Bhattacharya, R. Gupta, and P. K. Bhattacharjee, "Effect of low pressure alkaline delignification process on the production of nanocrystalline cellulose from rice husk," Journal of the Taiwan Institute of Chemical Engineers, vol. 80, no. Supplement C, pp. 820-834, Nov. 2017, doi: 10.1016/j.jtice.2017.06.042.

[43] T.-H. Liou, "Evolution of chemistry and morphology during the carbonization and combustion of rice husk," Carbon, vol. 42, no. 4, pp. 785-794, Jan. 2004, doi: 10.1016/j.carbon.2004.01.050.

[44] Y. Shen, P. Zhao, Q. Shao, D. Ma, F. Takahashi, and K. Yoshikawa, "In-situ catalytic conversion of tar using rice husk char-supported nickel-iron catalysts for biomass pyrolysis/gasification," Applied Catalysis B: Environmental, vol. 152-153, no. Supplement C, pp. 140-151, Jun. 2014, doi: 10.1016/j.apcatb.2014.01.032.

[45] Y.-Y. Hsieh et al., "Rice husk agricultural waste-derived low ionic content carbon-silica nanocomposite for green reinforced epoxy resin electronic packaging material," Journal of the Taiwan Institute of Chemical Engineers, vol. 78, no. Supplement C, pp. 493-499, Sep. 2017, doi: 10.1016/j.jtice.2017.06.010.

[46] P. Fu et al., "Evolution of char structure during steam gasification of the chars produced from rapid pyrolysis of rice husk," Bioresource Technology, vol. 114, no. Supplement C, pp. 691-697, Jun. 2012, doi: 10.1016/j.biortech.2012.03.072.

[47] L. Muniandy, F. Adam, A. R. Mohamed, and E.-P. Ng, "The synthesis and characterization of high purity mixed microporous/mesoporous activated carbon from rice husk using chemical activation with $\mathrm{NaOH}$ and KOH," Microporous and Mesoporous Materials, vol. 197, no. Supplement C, pp. 316-323, Oct. 2014, doi: 10.1016/j.micromeso.2014.06.020.

[48] T.-H. Liou, "Evolution of chemistry and morphology during the carbonization and combustion of rice husk," Carbon, vol. 42, no. 4, pp. 785-794, Jan. 2004, doi: 10.1016/j.carbon.2004.01.050.

[49] W.-Y. Lou, M.-H. Zong, and Z.-Q. Duan, "Efficient production of biodiesel from high free fatty acid-containing waste oils using various carbohydrate-derived solid acid catalysts," Bioresource Technology, vol. 99, no. 18, pp. 8752-8758, Dec. 2008, doi: 10.1016/j.biortech.2008.04.038.

[50] R. Zhong and B. F. Sels, "Sulfonated mesoporous carbon and silica-carbon nanocomposites for biomass conversion," Applied Catalysis B: Environmental, vol. 236, pp. 518-545, Nov. 2018, doi: 10.1016/j.apcatb.2018.05.012. 
[51] Y.-F. Huang, P.-T. Chiueh, W.-H. Kuan, and S.-L. Lo, "Microwave pyrolysis of lignocellulosic biomass: Heating performance and reaction kinetics," Energy, vol. 100, pp. 137-144, Apr. 2016, doi: 10.1016/j.energy.2016.01.088.

[52] A. A. Salema and F. N. Ani, "Microwave induced pyrolysis of oil palm biomass," Bioresource Technology, vol. 102, no. 3, pp. 3388-3395, Feb. 2011, doi: 10.1016/j.biortech.2010.09.115.

[53] T.-H. Liou, "Preparation and characterization of nano-structured silica from rice husk," Materials Science and Engineering: A, vol. 364, no. 1, pp. 313-323, Jan. 2004, doi: 10.1016/j.msea.2003.08.045.

[54] N. B. Machado, J. P. Miguez, I. C. A. Bolina, A. B. Salviano, R. A. B. Gomes, O. L. Tavano, J. H. H. Luiz, P. W. Tardioli, E. C. Cren, A. A. Mendes, "Preparation, functionalization and characterization of rice husk silica for lipase immobilization via adsorption," Enzyme and Microbial Technology, vol. 128, pp. 921, Sep. 2019, doi: 10.1016/j.enzmictec.2019.05.001.

[55] I. C. A. Bolina, A. B. Salviano, P. W. Tardioli, E. C. Cren, A. A. Mendes, "Preparation of ionexchange supports via activation of epoxy-SiO2 with glycine to immobilize microbial lipase - Use of biocatalysts in hydrolysis and esterification reactions," International Journal of Biological Macromolecules, vol. 120, pp. 2354-2365, Dec. 2018, doi: 10.1016/j.ijbiomac.2018.08.190.

[56] L. Ludueña, D. Fasce, V. A. Alvarez, and P. M. Stefani, "Nanocellulose from rice husk following alkaline treatment to remove silica," BioResources, vol. 6, no. 2, pp. 1440-1453, Mar. 2011, doi: 10.15376/biores.6.2.1440-1453.

[57] O. Levenspiel, Chemical Reaction Engineering, Third. New York: John Wiley \& Sons, 1972.

[58] H. S. Fogler, Element of Chemical Reaction Engineering, Third Edition. Prentice-Hall India, 2006.

[59] E. Sinin, "Synthesis, characterization and reactivity of sulfonated-platinum carbon-based bifunctional catalysts," Universiti Malaysia Sabah, Kota Kinabalu, 2017.

[60] F. A. Dawodu, O. Ayodele, J. Xin, S. Zhang, and D. Yan, "Effective conversion of non-edible oil with high free fatty acid into biodiesel by sulphonated carbon catalyst," Applied Energy, vol. 114, pp. 819-826, Feb. 2014, doi: 10.1016/j.apenergy.2013.10.004.

[61] M. Li, D. Chen, and X. Zhu, "Preparation of solid acid catalyst from rice husk char and its catalytic performance in esterification," Chinese Journal of Catalysis, vol. 34, no. 9, pp. 1674-1682, Sep. 2013, doi: 10.1016/S1872-2067(12)60634-2.

[62] M. Li, Y. Zheng, Y. Chen, and X. Zhu, "Biodiesel production from waste cooking oil using a heterogeneous catalyst from pyrolyzed rice husk," Bioresource Technology, vol. 154, pp. 345-348, Feb. 2014, doi: 10.1016/j.biortech.2013.12.070.

[63] X. Mo, E. Lotero, C. Lu, Y. Liu, and J. G. Goodwin, "A Novel Sulfonated Carbon Composite Solid Acid Catalyst for Biodiesel Synthesis," Catal Lett, vol. 123, no. 1-2, pp. 1-6, Mar. 2008, doi: 10.1007/s10562-008-9456-y. 
827 [64] G. Chen and B. Fang, "Preparation of solid acid catalyst from glucose-starch mixture for 828 biodiesel production," Bioresource Technology, vol. 102, no. 3, pp. 2635-2640, Feb. 2011, doi:

829 10.1016/j.biortech.2010.10.099.

830 [65] M. Hara, "Biodiesel Production by Amorphous Carbon Bearing SO3H, $\mathrm{COOH}$ and Phenolic $\mathrm{OH}$ 831 Groups, a Solid Brønsted Acid Catalyst," Top Catal, vol. 53, no. 11, pp. 805-810, Jul. 2010, doi:

832 10.1007/s11244-010-9458-z.

833 [66] E. Crabbe, C. Nolasco-Hipolito, G. Kobayashi, K. Sonomoto, and A. Ishizaki, "Biodiesel production 834 from crude palm oil and evaluation of butanol extraction and fuel properties," Process Biochemistry, vol. 835 37, no. 1, pp. 65-71, Sep. 2001, doi: 10.1016/S0032-9592(01)00178-9. 